\title{
QUEBRADA TACAHUAY: UN SITIO MARÍTIMO DEL PLEISTOCENO TARDÍO EN LA COSTA SUR DEL PERÚ
}

\author{
QUEBRADA TACAHUAY: A LATE PLEISTOCENE MARITIME SITE \\ ON THE SOUTH COAST OF PERU
}

\author{
Susan D. deFrance* y Adán Umire Álvarez**
}

\begin{abstract}
Presentamos un sumario de los trabajos arqueológicos realizados en la Quebrada Tacahuay, ubicada en el extremo sur de la costa peruana. Luego de una catastrófica inundación a consecuencia de un evento de El Niño que selló el primer nivel cultural fechado ca. 10.700 años a.p., se descubrieron reocupaciones menores del sitio, indicadas por desechos de moluscos acumulados en tres depósitos de poca profundidad. Eventos subsecuentes de inundaciones y depósitos geológicos de arena eólica sellaron los depósitos culturales. Tres temporadas de trabajo de campo han producido abundantes restos de subsistencia de la ocupación de 10.700 años a.p., instrumentos líticos, desechos de talla y rasgos relacionados con la preparación de alimentos, particularmente fogones. Estos contextos materiales indican una especialización en el procesamiento de aves marinas, principalmente cormoranes y piqueros, que fueron procesados, preparados y desechados. Otros tipos de restos de alimentos marinos incluyen huesos de pescado y conchas, que fueron también recolectados. No se ha encontrado evidencias de caza terrestre ni de la adquisición de material lítico de fuentes externas a la zona. El sitio provee datos sobre la antigüedad de las adaptaciones costeras de la región y el papel que jugó el fenómeno de El Niño en los asentamientos tempranos y colonización andina.
\end{abstract}

Palabras claves: economía marítima, inundaciones de El Niño, aves marinas.

We present a summary of the archaeological work that has been completed at Quebrada Tacahuay located on the far southern coast of Peru. Following a catastrophic El Niño flood event that sealed the earliest cultural layer dated to more than 10,700 years ago, there was minor reoccupation of the site as indicated by shellfish refuse and thin midden deposits. Subsequent flood events and geological deposits of aeolian sand sealed the cultural deposits. Three seasons of field work have produced abundant subsistence remains, lithic tools and debitage, and features related to food preparation, particularly hearths. These excavations indicate that the site was a specialized marine bird processing locale where large numbers of seabirds, primarily cormorants and boobies, were processed, prepared, and discarded. Some other marine foods including bony fishes and shellfish were also collected. There is no indication of terrestrial hunting nor of the acquisition of lithic material from non-local sources. The site provides data on the antiquity of coastal adaptations in the region and probable role of El Niño phenomena in early Andean colonization and settlement.

Key words: maritime economy, El Niño flooding, seabirds.

Quebrada Tacahuay representa una de las más antiguas expresiones de adaptación marítima en las Américas, con depósitos iniciales que datan del Pleistoceno tardío y una reocupación menor en el sitio durante el Holoceno temprano y medio (deFrance en revisión a; deFrance 2002; deFrance et al. 1998; 1999; 2001; Keefer et al. 1998; 2003) (Figura 1). Presenta una temprana actividad especializada en el sitio fechada alrededor de 10.700 años radiocarbónicos a.p. (todas las dataciones mencionadas en el texto se encuentran sin calibrar), enfocada a la explotación de avifauna marina. Los contextos más antiguos de actividad humana en Tacahuay son también llamativos debido a la naturaleza de su preservación, descubrimiento e inves- tigaciones arqueológicas. A pesar que muchas áreas del litoral andino pudieron ser ocupadas durante el Pleistoceno tardío, se encuentran relativamente pocos sitios ubicados en espacios donde la línea costera es muy estrecha, por lo que no han sido afectados por el aumento del nivel del mar hacia el fin de la Era Glacial (Richardson 1998). Adicionalmente, la preservación de los depósitos antrógenos más antiguos en Quebrada Tacahuay es el resultado de la caída de un huayco detonado por un evento paleoclimático ENSO, a lo que se sumaron subsecuentes eventos de huaycos y acumulaciones naturales de arena eólica que sellaron la ocupación más temprana y evidencias de tres ocupaciones más recientes (Keefer et al. 1998; 2003). Los depósitos

\footnotetext{
* Department of Anthropology, PO Box 117305, University of Florida, Gainesville, Fl, 32611. sdef@ anthro.ufl.edu

**Museo Contisuyo, Jr. Tacna 294, Moquegua, Perú.jmar_umirel@mixmail.com
} 


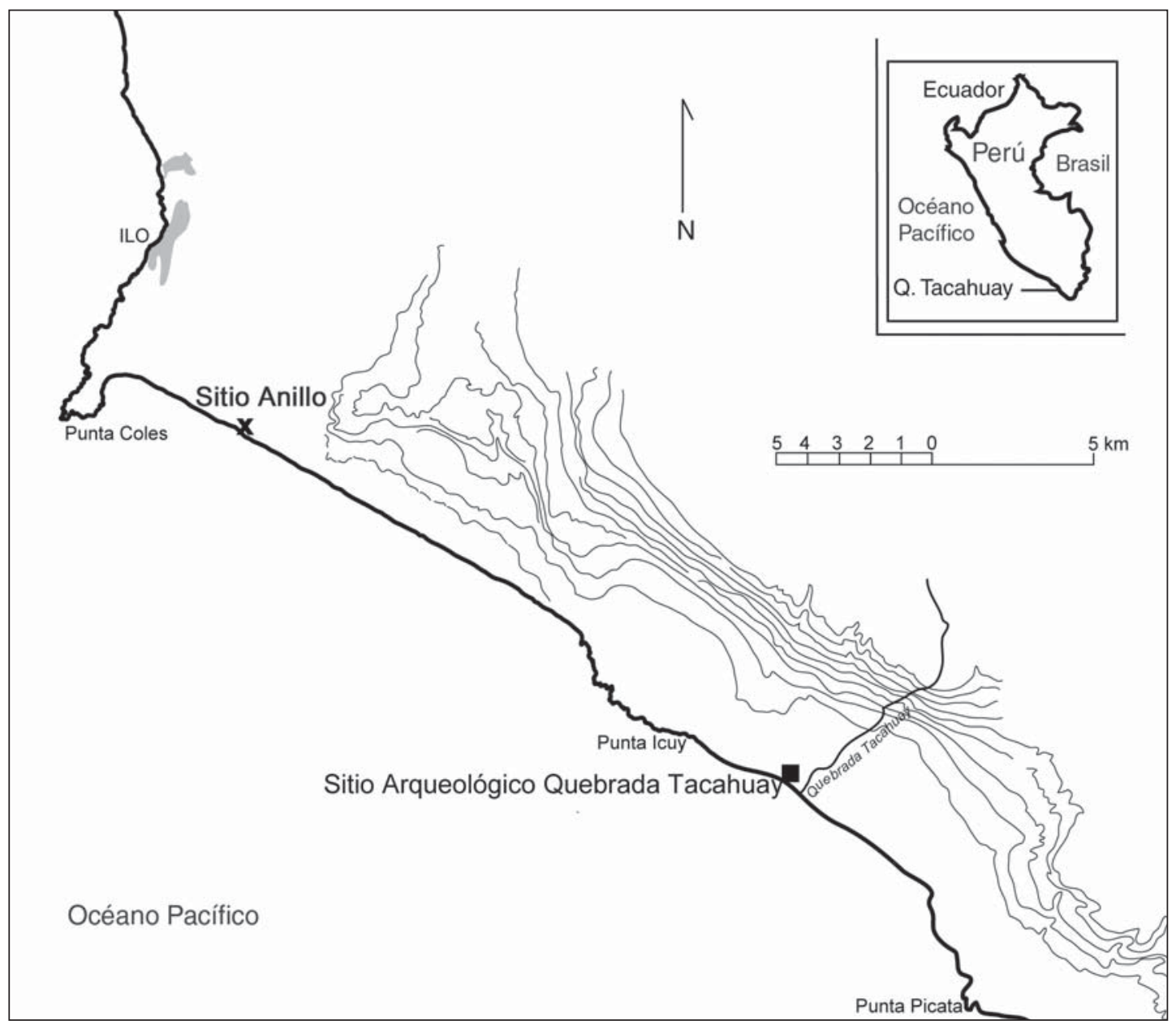

Figura 1. Ubicación del sitio Quebrada Tacahuay en el sur del Perú. Site location of Quebrada Tacahuay in Southern Peru.

quedaron expuestos a mediados de los años noventa durante la construcción de la carretera costanera que conecta la ciudad de Ilo y la comunidad de Ite, en el sur del Perú. Una prospección de la región identificó la ocupación, profundamente enterrada, a partir de una serie de cortes en la carretera y en perfiles de la quebrada. Se condujeron investigaciones arqueológicas y geológicas en el sitio en los años 1996, 1997, 1998 y 2001, siendo la última temporada de campo la más extensa (deFrance 2002; deFrance et al. 1998; 1999; 2001; Keefer et al. 1998).

En este artículo discutiremos los métodos y resultados de la temporada de campo del 2001, cómo la Quebrada de Tacahuay nos ayuda en el entendimiento de los más tempranos habitantes del litoral de los Andes Centro Sur, y algunas reco- mendaciones para futuras excavaciones de otros sitios tempranos.

En las temporadas de campo de 1997 y 1998 se recuperó evidencia inequívoca que indicaba una especialización de subsistencia en el uso de recursos marinos, particularmente aves marinas y, en menor cantidad, moluscos y pescado, así como la producción lítica con rocas de origen local costero (deFrance et al. 2001; Keefer et al. 1998). Sin embargo, la naturaleza de estas investigaciones estuvo muy limitada debido al enterramiento de los depósitos arqueológicos bajo dos a tres metros de sedimento. Las temporadas de campo de 1997 y 1998 consistieron principalmente en la recolección de muestras volumétricas de material cultural expuesto, así como sedimentos geológicos y una limitada excavación en el sentido arqueológico tra- 
dicional. Los objetivos de la temporada de campo del 2001 fueron dirigidos hacia la problemática de subsistencia, así como a recuperar datos empíricos que incrementaran nuestro conocimiento del rango de fenómenos sociales asociados con estos tempranos habitantes costeros. Por ejemplo, ¿qué actividades aparte del procesamiento y preparación de alimentos se llevaron a cabo en el sitio?, ¿el sitio contiene evidencia de estructuras u otros desechos culturales que puedan elucidar la naturaleza de los asentamientos costeros, así como la adaptación e interacción marítima? Con el fin de responder a estas interrogantes, la temporada de campo del 2001 consistió en la excavación de grandes bloques de tierra en un esfuerzo por exponer áreas que pudieran contener rasgos culturales (e.g., huecos de postes, enterratorios humanos, contextos de procesamiento de material no alimenticio) y posiblemente nuevos tipos de material cultural (e.g., elementos no líticos o líticos de materias primas de fuentes distantes, instrumentos de hueso adicionales a la única costilla de mamífero marino trabajada encontrada en 1998) que podrían aclararnos el rango de las actividades y comportamiento del sitio.

Mientras que las investigaciones previas habían estudiado principalmente las unidades estratigráficas mostradas en el perfil de la carretera, la metodología del 2001 resultó en una excelente exposición horizontal de los contactos entre las unidades culturales y geológicas. Estas excavaciones a gran escala fueron exitosas en la exposición de dos depósitos culturales discretos (Unidades 4, 4c3 y 5B) que fecharon la ocupación más temprana; sin embargo, ésta sólo fue visible en una muy limitada sección en el corte de la carretera y los perfiles de la quebrada. La excavación de la ocupación del Pleistoceno tardío fue también exitosa en la exposición de áreas horizontales de ocupación con desechos densos de líticos y restos de subsistencia, así como varios rasgos de fogones, algunos de los cuales fueron sellados por materiales culturales posteriores, indicando un reuso del sitio más que un episodio único de ocupación. Las grandes excavaciones espaciales también expusieron estratos geológicos discretos (e.g., depósitos de yacimientos de agua y ceniza volcánica) bajo la ocupación humana que fueron difíciles de ver sólo en el perfil. No obstante, no se identificaron nuevos indicadores culturales o áreas de actividad en los depósitos más antiguos, lo que apoya la hipótesis que Tacahuay fue un sitio de extracción local en donde se llevaron a cabo un número limitado de actividades, aunque los pobladores habrían residido en algún otro lugar de la zona (deFrance et al. 2001; deFrance en revisión a).

\section{Ubicación del Sitio e Historia del Medio Ambiente}

Quebrada Tacahuay $\left(17.8^{\circ} \mathrm{S}, 71.1^{\circ} \mathrm{W}\right)$ está ubicada a aproximadamente $30 \mathrm{~km}$ al sur de Ilo, Perú, en el límite distal de un amplio abanico aluvial (Figura 1). Actualmente, el profundo canal de la quebrada que drena el prominente abanico está caracterizado por diversos depósitos del Cuaternario que incluyen huaycos de grano grueso y escombros con lentes de arena eólica y ceniza volcánica (Keefer et al. 2003:43). En la época de ocupación, el sitio se encontraba aproximadamente entre 0,7 y $0,9 \mathrm{~km}$ de la línea de playa y la quebrada era significativamente más superficial. Actualmente el sitio se encuentra entre 0,3 y $0,4 \mathrm{~km}$ de la costa sobre una terraza que mira hacia una playa rocosa-arenosa ubicada entre los promontorios de Punta Icuy, al norte y Punta Picata, al sur. Este sitio fue ocupado por primera vez cuando el nivel del mar se encontraba entre 60 y $70 \mathrm{~m}$ sobre el nivel actual (Bard et al. 1996), entonces la bahía podría haber estado significativamente más definida y protegida, convirtiéndose en un lugar atractivo para la explotación de sus recursos.

Hoy en día el clima de la costa es hiperárido con una precipitación mínima (ONERN 1976:86). Los sedimentos y depósitos indican que estas condiciones climáticas han prevalecido desde, por lo menos, el Pleistoceno tardío (e.g., falta de vegetación, pobre desarrollo del suelo, pocas inclusiones orgánicas y grietas rellenadas con arena eólica (Keefer et al. 2003:69). Los ríos más cercanos a Quebrada Tacahuay están en Ilo, al norte, y Locumba y Sama, al sur; nacen en las laderas occidentales de los Andes, donde se originan las inundaciones a causa de las precipitaciones entre los meses de diciembre a marzo; en sus cursos bajos, estos ríos atraviesan el desierto costero hiperárido. Las inundaciones disminuyen a través del año, siguiendo la estación lluviosa en la sierra. Con anterioridad a la culminación de un reciente proyecto de irrigación (Pasto Grande) el cauce del río Ilo estuvo seco la mayor parte del año, bajo una altitud aproximada de $1.200 \mathrm{msm}$. Sin embargo, en 
los Andes el agua también es proporcionada por una serie de manantiales costeros, los cuales emergen en las quebradas de la cordillera de la Costa, en el margen interior de la llanura costanera. En tiempos prehistóricos el cauce principal del río Ilo podría haber estado estacionalmente seco, con agua disponible sólo en el verano austral cuando las lluvias y nevadas en las zonas altas recargan el sistema. A pesar que el agua disponible en los manantiales costeros estuvo también relacionada con los patrones de precipitación en la sierra, un estudio de los patrones de descarga moderna indica que algunos manantiales generan agua a través de todo el año, mientras que otros son estacionalmente secos (Clement y Moseley 1991).

En la Quebrada Tacahuay la evidencia de un manantial costero incluye la presencia de un cauce principal; paleocanales dentro de la secuencia sedimentaria y yacimientos de limo en el estrato geológico contienen los materiales de la ocupación del Pleistoceno tardío (Keefer et al. 1998; 2003). Estos limos también sugieren corrientes pluviales, posiblemente como resultado de una actividad menor de El Niño. En ausencia de un tributario mayor y con un inadecuado excedente de lluvias para la supervivencia humana, el agua fresca pudo haber sido un factor limitante importante para el asentamiento humano si el manantial no generaba este recurso a través de todo el año (deFrance en revisión a). La presencia de agua probablemente atrajo habitantes a esta área a pesar que estaba distante de la costa durante la ocupación más temprana.

Las únicas circunstancias bajo las cuales ocurre un número significativo de precipitaciones en la franja costera andina están asociadas a eventos de El Niño. Las típicas lluvias torrenciales producidas por este evento en este árido paisaje generan severas inundaciones, así como el transporte de grandes cantidades de sedimentos desestabilizantes. En una escala global, El Niño pleistocénico está fechado en ca. 125.000 años a.p. (Hughen et al. 1999). Una síntesis de la frecuencia de los eventos de inundaciones de El Niño, basados en reconocimientos geológicos, análisis de sedimentos y registros modernos e históricos para la región de Ilo, incluyendo la Quebrada de Tacahuay, indica que han producido inundaciones y escombros con presencia variable durante el Holoceno y Pleistoceno tardío, siendo el depósito más antiguo fechado alrededor de 38.000 años a.p. (Keefer et al. 2003); otros depósitos muy antiguos de carácter similar no fechados sugieren que El Niño ha estado afectando esta región desde épocas anteriores a los 38.000 años a.p. Diferentes depósitos sedimentarios sugieren un período de alta actividad de El Niño en el Holoceno temprano, seguido por un hiato de actividad durante la mitad del Holoceno y una subsecuente actividad moderada a alta en el Holoceno tardío, alrededor del 4.600 años a.p. (Keefer et al. 2003). Significativamente, estos datos demuestran que la intensidad de los eventos fluctúan desde perturbaciones de pequeña escala hasta catastróficos Mega-Niños.

En la Quebrada de Tacahuay, dos depósitos masivos de escombros de inundaciones que datan del Pleistoceno tardío y del Holoceno temprano son más grandes en escala que muchos de los más severos eventos ENSO recientes (e.g., 1982-1983, 1992-1993 y 1997-1998). Uno de éstos (Unidad 7) ha sido interpretado como un evento producido por El Niño poco tiempo después de un terremoto de alta magnitud que desestabilizó grandes cantidades de sedimentos (Keefer et al. 2003:70). El hiato en la actividad de El Niño hacia la mitad del Holoceno, presente en Quebrada Tacahuay ha sido documentado en otras áreas de los Andes en asociación con asentamientos humanos y está también confirmado por evidencia paleoclimática para regiones geográficas externas a los Andes (Cole 2001; Fontugne et al. 1999; Hughen et al. 1999; Keefer et al. 1998; Riedinger et al. 2002; Rodbell et al. 1999; Rollins et al. 1986; Sandweiss 1986, 2003; Sandweiss et al. 1996, 1997; 2001; Tudhope et al. 2001; ver también la revisión de Keefer et al. 2003). A pesar que la moderna periodicidad de la actividad de El Niño parece haber surgido en los últimos 5.000 años, el fenómeno tiene una antigüedad mucho mayor.

La Serie Superior de estratos de Quebrada Tacahuay definida por Keefer et al. $(1998 ; 2003)$ (Tabla 1, Unidades 1-9, Figura 2) contiene depósitos arqueológicos relevantes que datan de aproximadamente 4.500 años a.p. hasta el Pleistoceno y con evidencia de ocupación humana (Unidades 4, $4 \mathrm{c} 3,5$ y 8$)^{1}$. Keefer completó la caracterización de la historia geológica de la sedimentación en colaboración con las investigaciones arqueológicas usando los perfiles de la carretera y de la quebrada durante las temporadas de campo de 1996, 1997 y 1998, así como una evaluación del área posterior al terremoto del 23 de junio del 2001. Un mega- 


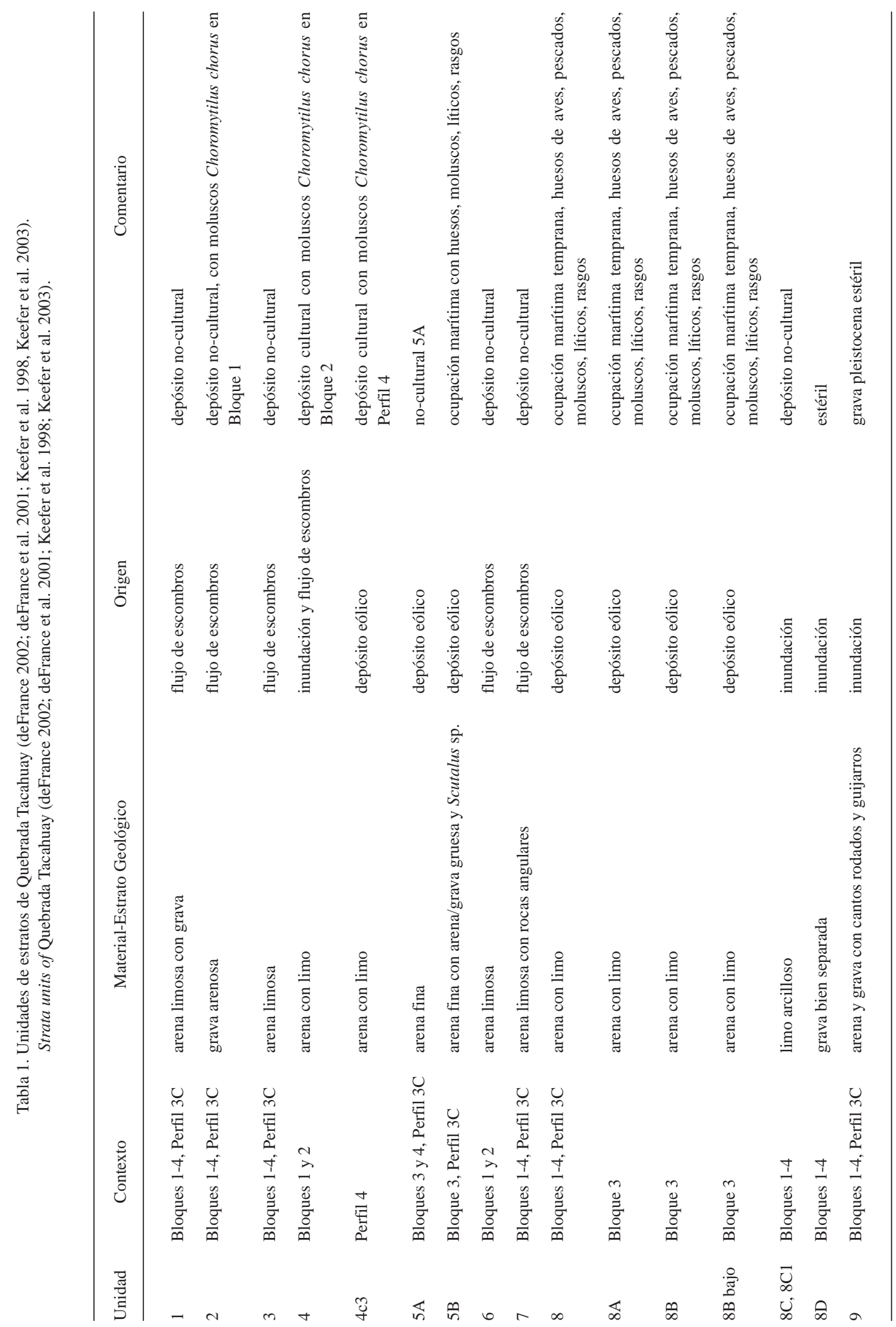




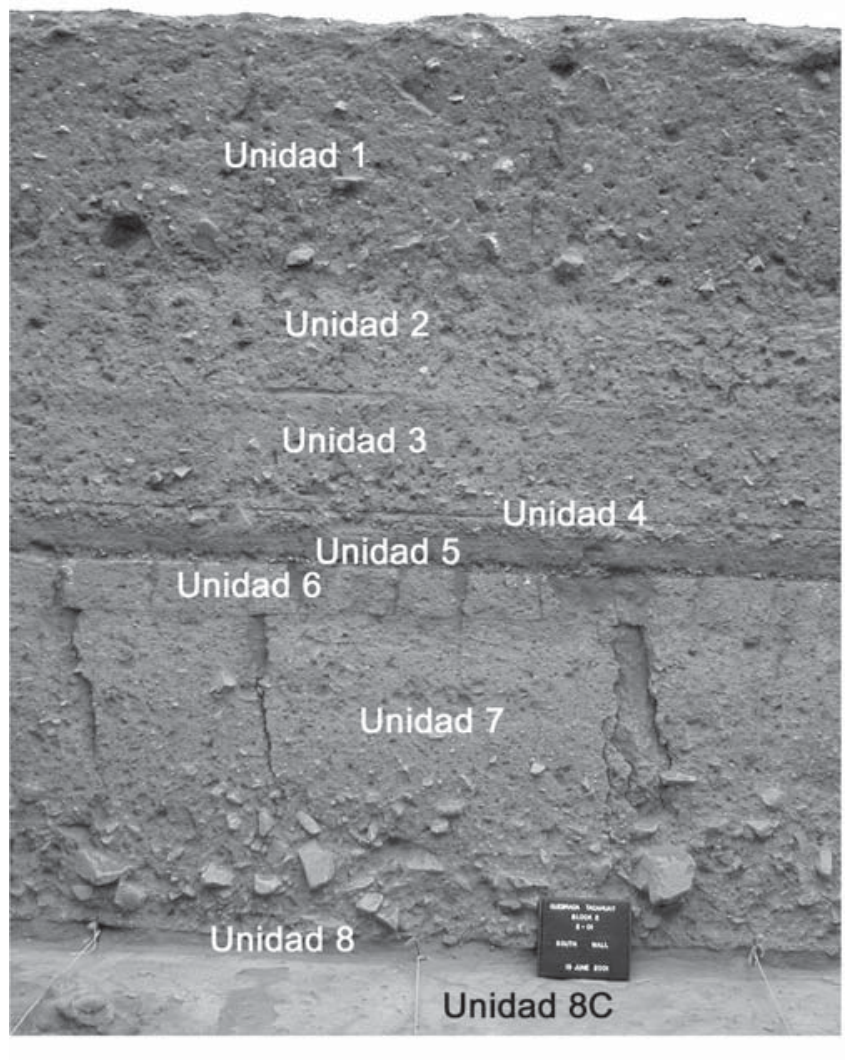

\author{
Bloque 2 \\ porción del \\ perfil sur
}

Bloque 1, detalle

de unidades

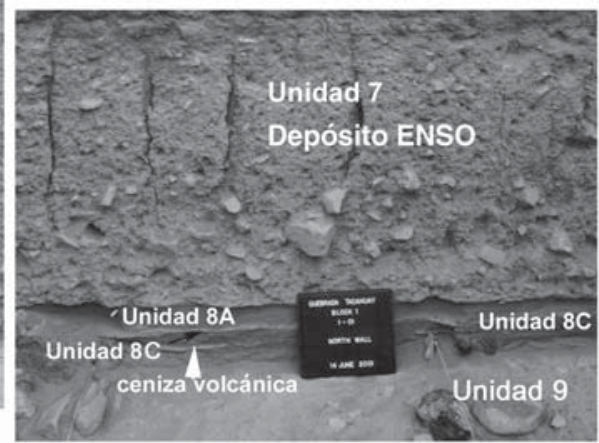

Figura 2. Perfil del Bloque 2, Unidades 1-8c de la pared sur y perfil del Bloque 1, detalle de la Unidad 8, pared norte.

Profile of portion of Block 2, south wall showing Units 1-8c and profile of portion of Block 1, north wall showing detail of Unit 8.

ENSO que produjo gran cantidad de escombros (Unidad 7) selló la ocupación humana más temprana (Unidad 8) bajo más de un metro de sedimento. Los análisis radiocarbónicos de los contextos arqueológicos bajo y sobre los depósitos de la Unidad 7 colocaron este evento entre el 10.290 y 10.090 años a.p. (deFrance et al. 2001). Los análisis de sedimentos indican que los escombros tuvieron una apariencia viscosa, caracterizada por una gran carga de sedimento de movimiento relativamente lento y distribución laminar, más que un movimiento rápido con líquido turbulento. Consecuentemente, los escombros sellaron el depósito antrógeno inicial, protegiéndolo en lugar de destruirlo. Algunos esqueletos de aves marinas que se encontraban sobre la superficie de la Unidad 8 quedaron adheridos en la base del escombro de la Unidad 7, mientras que los que estaban cubiertos con arena eólica quedaron protegidos, lo que indica que la sedimentación fue lenta.
Un segundo y delgado depósito de escombros (Unidad 6) se interpreta como un fenómeno relativamente rápido después de la Unidad 7, basado en las fechas radiocarbónicas que rodean las dos unidades (Keefer et al. 2003). La ocupación humana menor está presenta en las Unidades 4, 4c3 y 5. Depósitos adicionales de escombros acumulados en el sitio sellaron los depósitos antrógenos más recientes bajo 2 a $3 \mathrm{~m}$ de sedimento (Keefer et al. 1998; 2003). Después de la depositación de la Unidad 1 alrededor de 4.500 años a.p. la quebrada cortó un canal varias decenas de metros bajo el nivel de elevación alcanzado a esa época.

\section{Investigaciones Arqueológicas}

\section{Estudios preliminares}

En 1996 poco después de la construcción de la carretera costanera los investigadores realizaron 
un reconocimiento geoarqueológico del área identificando los depósitos arqueológicos recientemente expuestos en Quebrada Tacahuay. Una única fecha radiocarbónica procedente de un fogón erosionado de uno de los perfiles expuestos en la quebrada reveló la antigüedad (10.770 años a.p.) de un depósito de descarnado y procesamiento de aves marinas dentro de un lente de arena eólica (8-40 cm de profundidad). Los arqueólogos condujeron investigaciones limitadas en el sitio en 1997 y 1998 (deFrance et al. 2001; Keefer et al. 1998).

El objetivo de este proyecto fue identificar la naturaleza del uso temprano del sitio, y particularmente las actividades de subsistencia. Las investigaciones de 1997 y 1998 consistieron principalmente en la recolección de muestras volumétricas a lo largo de los perfiles de la carretera y de la quebrada; excavaciones horizontales mínimas (ocho cuadrículas de 1 x $1 \mathrm{~m}$ y una de 2,5 x $2 \mathrm{~m}$ ) conducidas en 1998 revelaron la presencia de restos de desecho lítico y huesos de aves bien conservados (deFrance et al. 2001; Keefer et al. 1998) ${ }^{2}$. Otros fogones pequeños se identificaron y excavaron parcialmente de los perfiles; sin embargo, las excavaciones horizontales de 1998 no revelaron rasgos in situ. La colección y análisis de la muestra volumétrica cernida en malla fina (malla de 1/16", 1,8 mm) de las temporadas de 1997 y 1998, así como de las excavaciones espaciales limitadas, fue exitosa en la obtención de abundante basura de fauna, una variedad de instrumentos líticos unifaciales y abundantes desechos como plantas carbonizadas apropiadas para fechado radiocarbónico (deFrance et al. 2001; Keefer et al. 1998). Este conjunto de datos proveyó evidencia incuestionable de una economía marítima especializada basada en la explotación y procesamiento (e.g., descarnado, cocina y consumo) de numerosos cormoranes y piqueros, con un menor uso de especies de peces y moluscos. Los restos de fauna también incluyeron algunos restos de foca o lobo de mar, indicando la caza activa u ocasional de mamíferos marinos. Las fuentes líticas costeras proveyeron de calcedonia para la producción de herramientas para cortar y raspar. Los habitantes del sitio no consumieron ningún tipo de animal terrestre, lo que es consecuente con la ausencia de materiales líticos para cazar este tipo de fauna, y materias primas provenientes de otras elevaciones o hábitats. Quebrada Tacahuay es interpretado como un sitio especializado de procesamiento y extrac- ción marítima local que fue preservado debido a que quedó cubierto con sedimentos de eventos paleoclimáticos fortuitos y catastróficos (deFrance en revisión a; deFrance et al. 2001; Keefer et al. 1998; 2003).

A pesar de haber establecido el patrón de explotación de fauna, la tecnología predominante y la ubicación cronológica de los depósitos del sitio, poco es lo que se conoce sobre la ocupación del sitio y los habitantes costeros más tempranos. La naturaleza limitada de las excavaciones nos ha permitido la recuperación de materiales culturales, pero el contexto de su uso y comportamiento, aparte del procesamiento y preparación de los restos de fauna, se encuentra aún indefinido. De este modo, la naturaleza del tipo de residencia costera todavía es desconocida. ¿Los habitantes vivían en el sitio durante todo el año, o sólo estacionalmente, o fue un sitio de una única ocupación en donde una gran cantidad de aves y algunos otros animales fueron cazados, procesados y consumidos?

\section{Excavaciones arqueológicas}

La temporada de campo del año 2001 consistió en la excavación de cuatro bloques de cuadrículas de 5 x $5 \mathrm{~m}$, en áreas donde los depósitos de la Unidad 8 se encontraban intactos (e.g., las investigaciones previas habían recuperado abundante material cultural de los depósitos expuestos de la Unidad 8 en varios perfiles) (Figura 3 ). Con el fin de alcanzar la Unidad 8, excavamos 2-3 m de un estrato estéril usando picos y palas. Una vez que los depósitos culturales intactos fueron identificados, el bloque fue subdividido usando cuadrículas de $1 \mathrm{~m}^{2}$ excavándose los depósitos con badilejo. Como en las temporadas anteriores, el material fue cernido en malla de $1 / 16$ " $(1,8 \mathrm{~mm})$ y guardado para su clasificación en el laboratorio.

La excavación de los cuatro bloques tuvo varios grados de éxito en la ubicación de materiales culturales únicos. El Bloque 1 (Figura 3) fue colocado en un área a lo largo del pequeño perfil designado como $1 \mathrm{~A}$, donde en las excavaciones previas se recuperó abundantes desechos líticos y algunos instrumentos asociados a la Unidad 8. Siguiendo la excavación de la Unidad 1 en el Bloque 1, descubrimos una dispersión muy delgada (un grosor máximo de $5 \mathrm{~cm}$ ) de conchas marinas (Choromytilus chorus) en contacto entre las Unidades 1 y 2 , dispersión que no había sido identificada pre- 


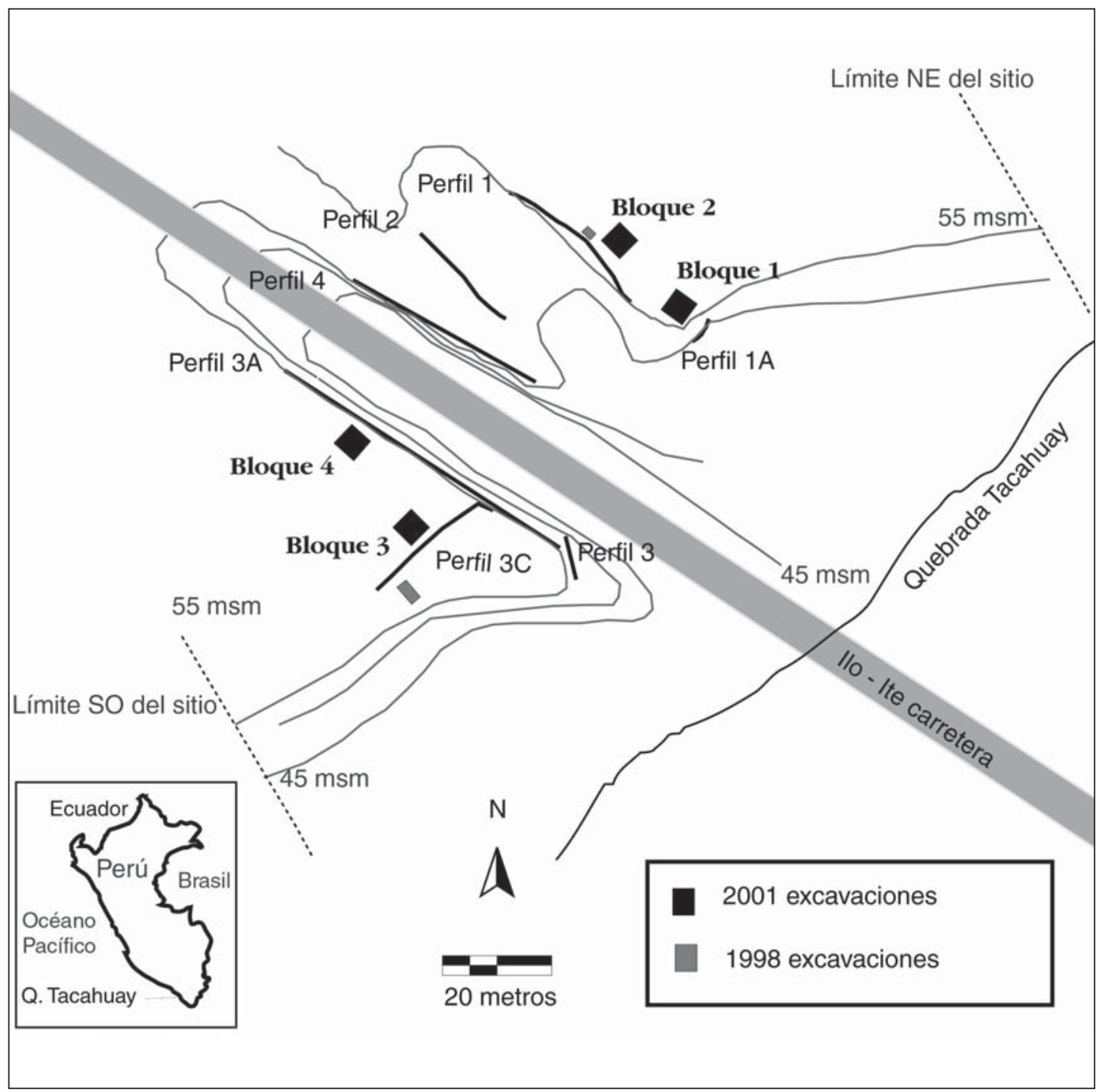

Figura 3. Quebrada y sitio arqueológico de Tacahuay. Ubicación de las excavaciones del año 2001 y temporadas previas. Location of 2001 and previous excavations, at Quebrada Tacahuay archaeological site.

viamente en ninguno de los perfiles de las excavaciones. No se encontró material cultural junto con la dispersión. A pesar que el lente de concha no fue fechado directamente, las fechas de las Unidades 1 y 2 ubican este depósito de conchas en algún momento entre $4.500 \pm 60$ y $7.920 \pm 80$ años a.p. Una vez que expusimos los depósitos de la Unidad 8, sólo encontramos escasos restos de subsistencia y material lítico. Una extensión sur de la excavación $(0,85$ × 2 m del límite del perfil) en el área del Perfil $1 \mathrm{~A}$ se recuperó algún material lítico adicional, pero no un área de actividad clara. Si existió un taller lítico en esta área, posiblemente se destruyó cuando los sedimentos del sitio fueron removidos con la construcción del canal principal.

El Bloque 2 fue ubicado al noreste del Perfil 1 cerca del primer fogón que muestreamos y donde excavamos una cuadrícula de 2 x 1,5 m en 1998 (Figura 3). En la superficie de la Unidad 4 descubrimos una delgada dispersión amorfa (dimensiones máximas de 1,54 m este-oeste x 1,45 m nortesur) de Choromytilus chorus y carbón, a lo largo de la pared este. El lente no contuvo ningún material artefactual ni otros restos de fauna aparte de 
las conchas. Este depósito cultural está también presente en el Perfil 4; sin embargo, el lente de concha no se encuentra a través del sitio y sólo fue ubicado en esta unidad de excavación. Un único fechado AMS de carbón produjo una fecha de $9.010 \pm 40$ años a.p. Una vez que los depósitos fueron excavados en el Bloque 2, encontramos una pequeña dispersión de material cultural de Unidad 8 que incluye huesos de aves, pero sin rasgos culturales o concentraciones de basura. No obstante, una vez excavada la Unidad 8 y expuesto el lente limoso (Unidad 8C) y los depósitos estériles del Pleistoceno de la Unidad 9, encontramos los restos de un pequeño canal de agua corriendo en dirección este-oeste a través de toda la parte norte del bloque (Figura 4). Los sedimentos de agua indican que el canal llevó agua de un manantial u otra fuente de agua pluvial hacia la acumulación de arena eólica de la Unidad 8.

El Bloque 3 fue el más productivo en proporcionar materiales culturales (Figura 3). El Bloque 3, adyacente a los Perfiles 3C, contuvo abundantes depósitos arqueológicos bien conservados, tanto en la Unidad 5 como en la 8. La Unidad 5 es un depósito de arena eólica con limo que contiene ocupación humana que data entre $9.850 \pm 150$ a 10.090 \pm 130 años a.p. (Tabla 3). La visión en el corte del perfil es homogénea; sin embargo, la excavación horizontal del estrato consiste de dos lentes de arena distintivos. Existe un nivel superior de arena estéril de aproximadamente $8-10 \mathrm{~cm}$ de profundidad (Unidad 5A) y una segunda capa de un lente compacto de arena con grava y material cultural (Unidad 5B) de aproximadamente $16-18 \mathrm{~cm}$ de profundidad. La Unidad 5B contiene abundantes restos de caracoles de tierra, Scutalus sp.; sin embargo, estos pequeños caracoles son considerados una especie no comestible, encontrados en asociación con la basura generada por la población. En el hábitat de desierto costero, abundantes caracoles terrestres esperan hasta que haya suficiente humedad para soportar el crecimiento de la población (ver Craig 1992). La abundancia de caracoles de tierra en asociación con basura sugiere que fue más húmedo en la época en que la Unidad 5B fue depositada; no obstante, no tenemos datos que corroboren esta hipótesis. Una vez que alcanzamos la techo de la Unidad 5, el bloque entero fue seccionado en cuadrículas de $1 \mathrm{~m}^{2}$. El material cultural recuperado de la Unidad 5B incluye lascas de calcedonia y basalto, así como raspadores de ba- salto costero. También se encontró restos de fauna vertebrada e invertebrada. Uno de los rasgos arqueológicos, un fogón amorfo, fue excavado a lo largo de la pared norte del bloque (Tabla 2). No se encontró evidencia de preparación superficial para el fogón.

Siguiendo la excavación de la Unidad 5B, usamos picos y palas para excavar los escombros de los depósitos de la Unidad 7 (la Unidad 6, el depósito de escombros más delgado generado por el ENSO, no fue encontrada en esta parte del sitio). Una vez que los depósitos de la Unidad 8 fueron expuestos, establecimos otra vez el sistema de cuadriculación de $1 \mathrm{~m}^{2}$ para el bloque. A pesar que la matriz de arena dentro de la Unidad 8 fue uniforme, definimos y excavamos cuatro subunidades discretas de material cultural que se distinguieron por el grado de fragmentación de los huesos, ubicación estratigráfica e integración a la unidad de arena. Estos estratos no se pudieron definir en el perfil debido al color y textura uniforme de la arena de la Unidad 8.

La capa de fragmentos de huesos descubierta en el techo de la Unidad 8 y cementada dentro de la base de la Unidad 7 fue designada como Unidad 8A. Estos especímenes todavía no habían sido sellados por la arena eólica antes del evento de la depositación de escombros. Una capa gruesa de elementos óseos enterrados, definida como Unidad 8B, incluyó abundantes huesos completos, algunos de los cuales se encontraban parcialmente articulados (e.g., ulna y húmero, varias vértebras cervicales, escápula y el coracoide y las falanges). Designamos los niveles consecutivos de huesos fragmentados y completos como Unidad 8B Nivel 2 y un nivel más profundo de huesos y rasgos culturales cubiertos totalmente por la arena eólica como Unidad 8B Bajo.

La Unidad 8B contiene cinco fogones: Rasgos 2, 3, 4, 5 y 6 (Tabla 2). Los Rasgos 4 y 6 fueron enterrados por arena y presentaban elevaciones ligeramente más profundas que los Rasgos 2 , 3 y 5 ; por consiguiente, la designación contextual Unidad 8B Bajo fue usada para distinguir la ubicación estratigráfica de los Rasgos 4 y 6 . Todos los rasgos fueron seccionados y excavados en dos mitades para exponer sus perfiles. El Rasgo 3 mostrado en la Figura 5 no contuvo estratos internos; sin embargo, varios elementos articulados estuvieron presentes en superficie. Como en el caso del Rasgo 1 en la Unidad 5B, no existió una prepara- 

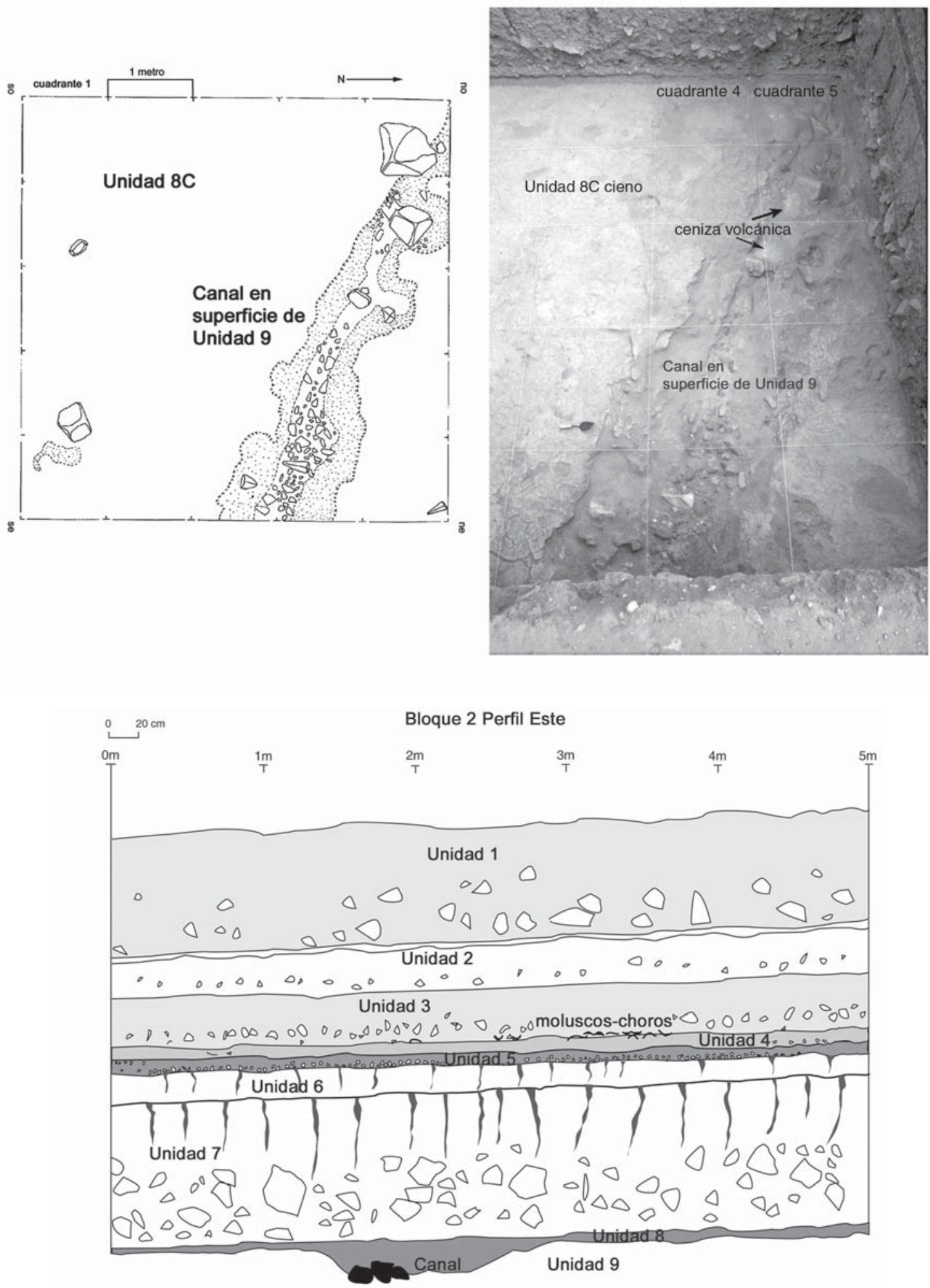

Figura 4. Remanente del canal en Bloque 2, superficie de la Unidad 9.

Remnant channel in Block 2, Unit 9 surface. 
Tabla 2. Descripción de los rasgos excavados en la temporada de campo del 2001. Description of the features excavated in the 2001 field season.

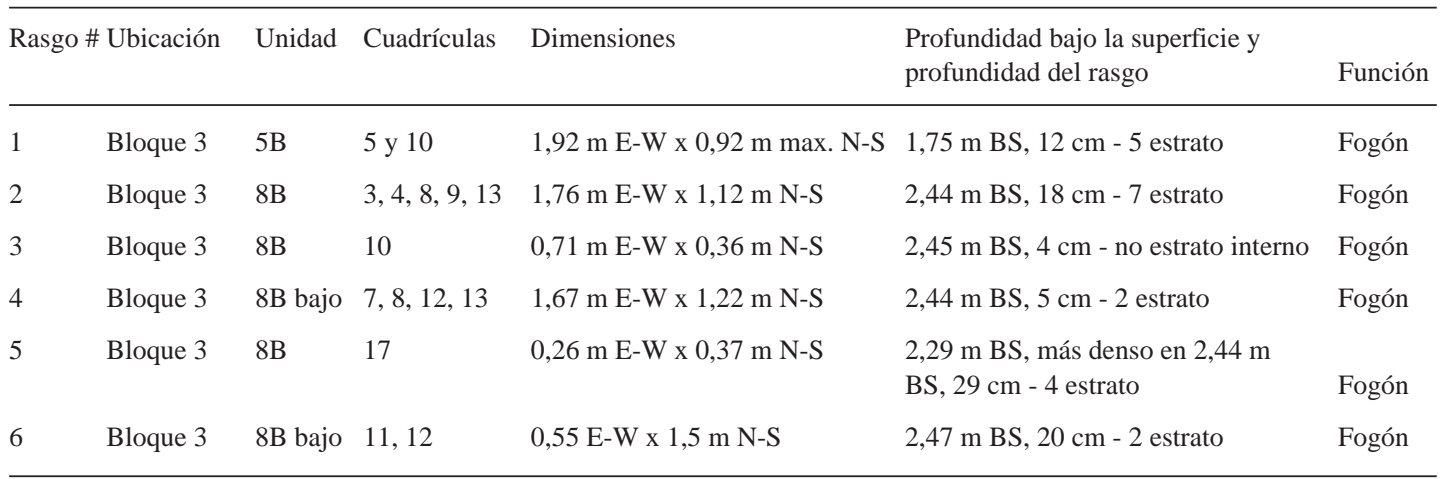

Rasgo 1 contiene carbón, fauna vertebrada, bivalvos marinos, con gasterópodo terrestre Scutalus sp. y un raspador de calcedonia costera.

Rasgos 2-6 contienen carbón, ceniza, elementos fragmentados y completos de aves y peces marinos, pequeñas cantidades de moluscos marinos.

Rasgos 2 y 4 también contienen herramientas y desechos líticos de calcedonia y una lasca de cuarzo rosado.

Rasgo 5 fue el más compacto con una densa masa de material botánico.

Tabla 3. Fechados radiocarbónicos de las unidades estratigráficas culturales 4c3, 5 y 8 en Quebrada Tacahuay.

Las fechas más recientes que $10.000 \mathrm{C} 14$ años a.p. fueron calibradas por Beta. Todos los fechados más antiguos que 10.000 años a.p. fueron calibrados usando INTCAL98 (Stuvier et al. 1998) y están expresados con 2 sigmas.

Todas las fechas han sido corregidas por fraccionamiento isotópico.

Radiocarbon dates of cultural stratigraphic units 4c3, 5 and 8 at Quebrada Tacahuay. The dates later than 10,000 14C B.P. were calibrated by Beta. All the dates earlier than 10,000 B.P. were calibrated with INTCAL98 (Stuvier et al. 1998) and they are presented with 2 sigma. All dates have been corrected through isotopic fraction.

\begin{tabular}{lccccc}
\hline $\begin{array}{c}\text { Contexto } \\
\text { (Perfil o Bloque/Unidad) }{ }^{\text {a }}\end{array}$ & ${ }^{14}$ C años a.p. & $\begin{array}{c}\text { Calibrado 2- } \sigma \\
\text { rangos cal años a.p. }\end{array}$ & $\begin{array}{c}\text { Muestra \# }{ }^{\mathrm{b}} \\
\text { y Técnica }\end{array}$ & $\delta^{13}$ C & Material \\
\hline Perfil 4 Unidad 4c3 & $7990 \pm 80$ & $9086-8596$ & 109354 Conv-97 & -21.9 & carbón \\
Bloque 2 Unidad 4 & $9010 \pm 40$ & $10230-10150$ & 172615 AMS-01 & -22.9 & carbón \\
Bloque 3 Unidad 5B & $9850 \pm 150$ & $11950-10970$ & 159921 Conv-01 & -25.6 & carbón \\
Perfil 3C Unidad 5B & $10050 \pm 90$ & $12280-11230$ & 160707 AMS-01 & -22.2 & carbón \\
Perfil 3B-Unidad 5 & $10090 \pm 130$ & $12340-11230$ & 122820 Conv-98 & -27.0 & carbón \\
Perfil 1A-Unidad 8 & $10290 \pm 200$ & $12886-11233$ & 126968 AMS-98 & -23.9 & carbón \\
Perfil 1A-Unidad 8 & $10420 \pm 110$ & $12886-11767$ & 122822 Conv-98 & -26.7 & carbón \\
Perfil 3B-Unidad 8 & $10510 \pm 50$ & $12909-12094$ & 122821 AMS-98 & -25.9 & carbón \\
Perfil 3A-Unidad 8 & $10530 \pm 140$ & $12948-11784$ & 108860 Conv-97 & -27.4 & carbón \\
Bloque 3 Unidad 8B bajo & $10660 \pm 80$ & $12960-12340$ & 160706 AMS-01 & -20.4 & carbón \\
Perfil 1A Unidad 8 (1998) & $10690 \pm 60$ & $12960-12380$ & 172645 AMS-01 & -25.7 & carbón \\
Perfil 1-Unidad 8 & $10750 \pm 80$ & $12992-12431$ & 108692 AMS-97 & -24.3 & carbón \\
Perfil 1-Unidad 8 & $10770 \pm 150$ & $13140-12345$ & 95869 Conv-97 & -27.1 & carbón \\
\hline
\end{tabular}

a Perfil se refiere al corte expuesto en la carretera o quebrada. Unidad se refiere tanto a niveles estratigráficos arqueológicos como geológicos.

b Todos los fechados corresponden a Beta Analytic, Inc; A se refiere a fechas AMS; C se refiere a fechas convencionales; año se refiere a temporada de campo. Los fechados de la temporada de 1997 son de Keefer et al. 1998; los fechados de la temporada de 1998 son de deFrance et al. 2001; los fechados de la temporada del 2001 son de deFrance en revisión b. 


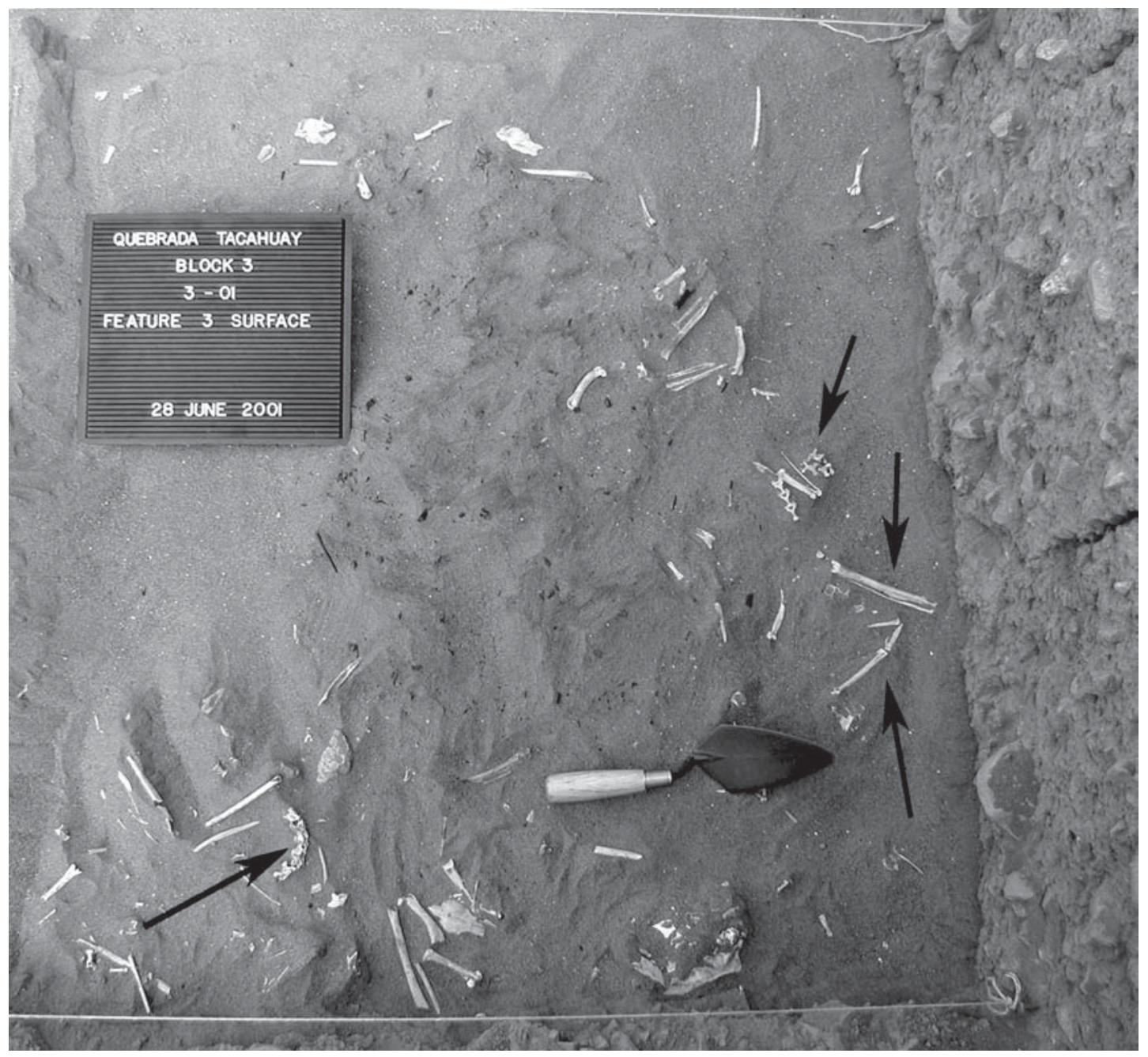

Figura 5. Superficie Rasgo 3, Bloque 3, cuadrícula 10 con ejemplos de elementos articulados de aves marinas. Feature 3 Surface, Block 3, quad 10 showing examples of articulated marine bird elements.

ción de la superficie para los fogones de la Unidad $8 \mathrm{~B}$; éstos no estaban definidos por piedras u otro material. Los fogones estuvieron conformados por lentes de ceniza, carbón y huesos de aves quemados y sin quemar junto con cantidades variables de restos de pescado y algunos moluscos y líticos.

Dado que la arena enterró por lo menos a dos de los rasgos, éstos quedaron en niveles estratigráficos más profundos que los otros fogones. La cantidad y distribución del material a través del sitio no sugiere un único episodio de caza, procesamiento y consumo de aves; sin embargo, no se conoce el tiempo que tomó todo el proceso de depositación cultural. Con todo, la acumulación y entierro de algunos de estos rasgos por arena eólica indica el reuso del sitio más que un único evento depositacional. Al igual que los fogones, los materiales culturales son similares a los identificados previamente en la Unidad 8. También son abundantes los restos de aves marinas y material lítico ${ }^{3}$.

El Bloque 4 está localizado al suroeste de la carretera costanera. En contraste con los depósitos del Bloque 3 de la Unidad 5, el Bloque 4 no tenía material cultural. Los depósitos de la Unidad 8 que contienen material cultural (Unidad 8A) fueron muy superficiales. Todo el material cultural estuvo restringido al depósito de arena de 8-10 cm con algunos fragmentos de huesos de ave y cinco fragmentos de moluscos marinos. En este bloque no se encontró líticos ni otros artefactos. 
Adicionalmente a la excavación de los cuatro bloques, como parte de la temporada de campo del 2001, se investigó los depósitos culturales de un perfil recientemente expuesto. El Niño de 19971998 causó la destrucción de un sector de la carretera costanera en la Quebrada de Icuy, al norte del sitio. El Ministerio de Transportes y Comunicaciones peruano removió los depósitos de Tacahuay para usarlos como relleno del camino en 1998 y una vez más entre 1998 y el 2000. Estas operaciones resultaron en la exposición del Perfil 3C (paralelo al Perfil 3B que fue muestreado en 1998) (Figura 2). El perfil sólo expuso el estrato de la superficie de la parte superior de la Unidad 8. La mayor parte de los depósitos de la Unidad 8 permanecieron cubiertos. A pesar que los depósitos culturales de la Unidad 8 permanecieron sin exponer, el nuevo perfil proveyó una excelente exposición de la Unidad 5. Restos de fauna, líticos y carbón de la Unidad 5 fueron erosionados a partir del depósito sobre la Unidad 7.

Nosotros seccionamos las partes mejor conservadas del perfil en catorce secciones de $1 \mathrm{~m} \mathrm{li-}$ neal. Todo el material cultural superficial de una sección de $14 \mathrm{~m}$ fue registrado y recolectado. Una vez que el perfil fue limpiado, se tomaron pequeñas muestras volumétricas de la porción intacta de la Unidad 5 a partir de nueve secciones de $1 \mathrm{~m}$. Los volúmenes recolectados tuvieron un promedio entre 3 a 6 litros. Todo el material fue cernido en malla fina y llevado al laboratorio para su clasificación y análisis. El Perfil 3C contuvo una regular cantidad de material cultural incluyendo líticos, concha marina, restos de fauna vertebrada y carbón. Las conchas de Scutalus sp. son comunes a través de todo el perfil. Estos datos complementan los hallazgos de las excavaciones de la Unidad 5B en el Bloque 3.

\section{Resultados de las excavaciones}

Se han realizado un total de trece fechados a partir de los estratos culturales en Quebrada Tacahuay; cinco de éstos pertenecen a muestras tomadas en el 2001 (Tabla 3 y Figura 6). Una fecha provino de un delgado depósito de choros (Unidad 4) descubierto en el Bloque 2. Dos de las fechas fueron de los depósitos culturales de la Unidad 5, incluyendo un fechado del Rasgo 1 y otro del Perfil 3C. Dos fechados adicionales de los depósitos de la Unidad 8 están dentro del rango de tiem- po de las muestras previas ${ }^{3}$. Cuando se comparan todas las fechas procedentes de los depósitos culturales, es evidente que el uso humano de la quebrada estuvo centrado en el Pleistoceno tardío y el Holoceno temprano (Figura 6). A pesar que no obtuvimos una fecha cronométrica para la delgada dispersión de choros presente en el Bloque 1, parece que éste fue un depósito muy localizado (e.g., esto no se repite en ninguna otra área del sitio). Esta dispersión de conchas fue depositada anterior a la Unidad 1 (4.500 años a.p.), y, de esta manera, puede ser contemporánea con la Unidad 2 (7.920 años a.p.) y con la única fecha de la Unidad 4c3 (7.990 \pm 80 años a.p.) (ver Keefer et al. 2003 para la discusión de las relaciones entre Unidades 2 y 4).

Las excavaciones a gran escala del 2001 son consistentes con los hallazgos previos con respecto a economía marítima y subsistencia. El sitio presenta evidencia para la extracción especializada y el procesamiento de un gran número de aves marinas y un uso menor de otros recursos costeros. La fauna marina identificada a partir de los depósitos de la Unidad 8, tanto del Bloque 3 como de la extensión sur del Bloque 1, es consistente con las temporadas de campo de 1997 y 1998 (Tabla 4). No existen restos de recursos terrestres que puedan ser considerados como alimenticios. Están presentes los restos de reptiles muy pequeños (e.g., lagartijas y serpientes), pero éstos no son considerados como componentes alimenticios humanos, dado el tamaño de los huesos, ca. 1,8 mm que corresponde al reticulado de la malla del harnero, por lo que pensamos que no sirvieron como alimento.

La temporada de campo del 2001 no recuperó material adicional para aclarar el método de captura de las numerosas aves marinas; estas aves pudieron ser capturadas con redes mientras estaban alimentándose en la orilla, o mientras anidaban en los roqueríos. El único artefacto de hueso recuperado en la temporada de 1998, una costilla de mamífero marino trabajada (Figura 7, superior), recuerda un calibrador de red, que permite la uniformidad de las aperturas en la elaboración de las mallas. El artefacto no presenta huellas de uso en los lados que indiquen su función como chope. Cormoranes, piqueros y pelícanos también habitaron en los roqueríos, por lo que la caza en ese lugar también podría haber estado acompañada por boleadoras de piedra u otra tecnología, cuyos restos se encontraron en las excavaciones previas, lo que incluyó huesos de aves $(\mathrm{n}=191)$ y dos frag- 

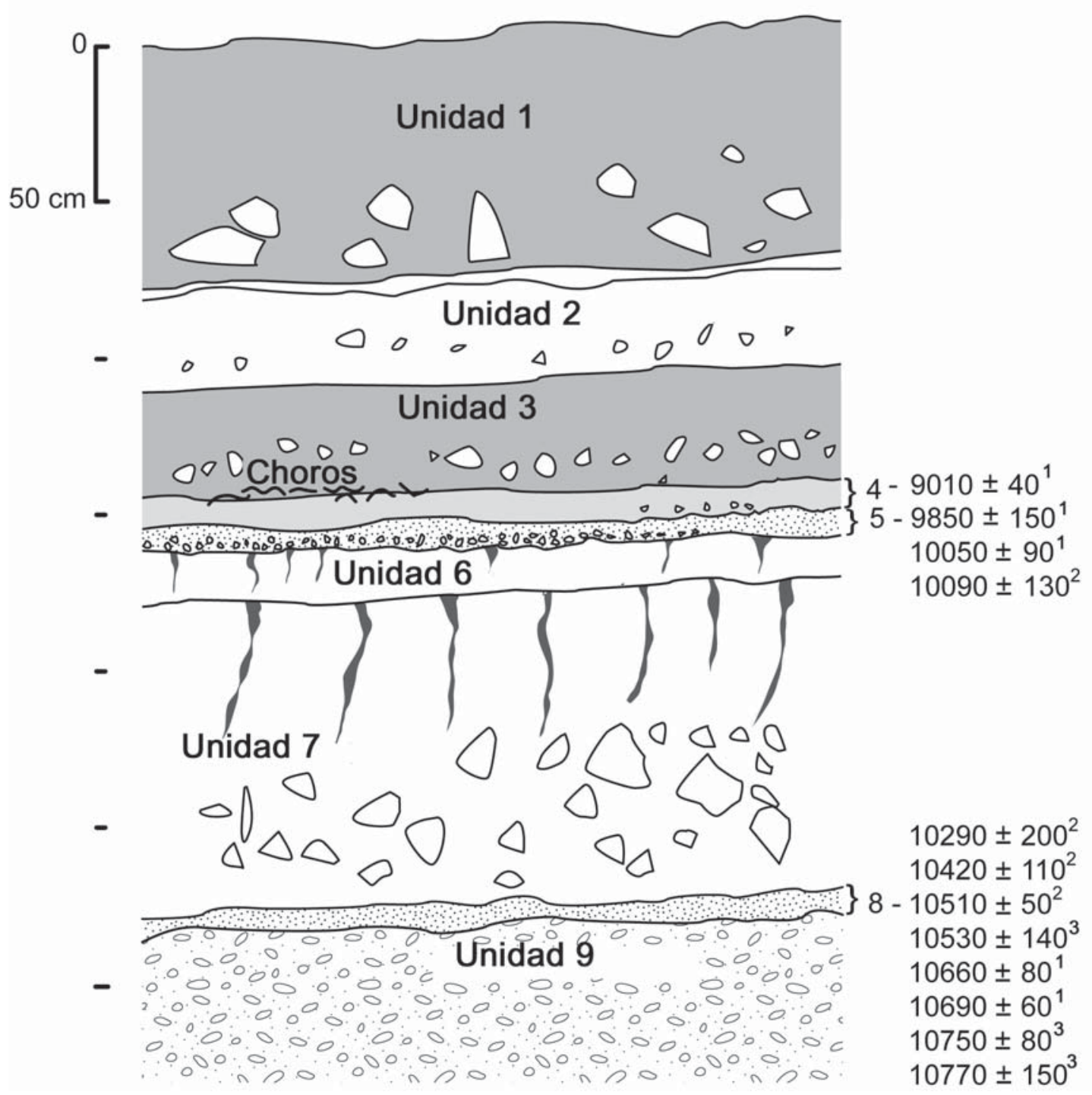

Figura 6. Perfil compuesto indicando los estratos y fechados radiocarbónicos asociados $\left({ }^{1}\right.$ fechas de deFrance en revisión b; ${ }^{2}$ fechas de deFrance et al. 2001; ${ }^{3}$ fechas de Keefer et al. 1998. Todos los materiales culturales [Unidades 4c3, 5 y 8] se encuentran dentro de los depósitos de arena eólica. Un lente de choro presente en la Unidad 4c3 no está descrito en este perfil).

Composite profile indicating cultural strata and associated radiocarbon dates $\left({ }^{1}\right.$ dates are from deFrance in review $b ;{ }^{2}$ dates are from deFrance et al. 2001; ${ }^{3}$ dates are from Keefer et al. 1998. All cultural materials [Units 4c3, 5, and 8] are within aeolian sand deposits. A choro mussell shell lense present in Unit $4 c 3$ is not depicted in this profile.)

mentos de hueso de mamíferos marinos con evidencia de descarnado (Figura 8). Los cinco fogones indican que muchos de los especímenes de aves fueron cocinados y presumiblemente consumidos en el sitio. El uso de redes también podría explicar la recolección de numerosos peces de tamaño pequeño.
Siguiendo al evento ENSO que enterró los depósitos de la Unidad 8, la reocupación humana del área (Unidad 5) estuvo caracterizada por la captura de aves marinas, y un incremento en la explotación de peces marinos y moluscos (Tabla 4) y ausencia de registros de restos marinos. El uso de los moluscos es muy variado e incluye especies no 
Tabla 4. Fauna identificada de la Unidad 5, Perfil 3C, Unidad 5B, Bloque 3 y Unidad 8 Bloque 3 y

Bloque 1 extensión sur, temporada de campo 2001.

Identified fauna from Unit 5, Profile 3C, Unit 5B, Blocks 3 and Unit 8, Block 3 and Block 1 south extension, 2001 field season.

\begin{tabular}{|c|c|c|c|c|c|}
\hline \multirow[b]{2}{*}{ Nombre científico } & & \multicolumn{2}{|c|}{ Unidad 5 y $5 \mathrm{~B}$} & \multicolumn{2}{|c|}{ Unidad 8} \\
\hline & & \# Fragmentos & NMI & \# Fragmentos & NMI \\
\hline Chiroptera & murciélagos & & & 1 & 1 \\
\hline Rodentia nn & roedores & 90 & 4 & 28 & 3 \\
\hline Canidae cf. Pseudalopex sechurae & zorro & 18 & 1 & & \\
\hline Arctocephalus sp. & lobo fino & & & 5 & 1 \\
\hline Otaria cf. flavescens & lobo chusco & & & 1 & 1 \\
\hline Otariidae/Phocidae & focas, lobos marinos & & & 2 & 1 \\
\hline Pinnipedia & focas, lobos marinos & & & 2 & 0 \\
\hline Mammal nn & mamífero indet. & 55 & 1 & 7 & 0 \\
\hline Total Mammalia & & 163 & 6 & 46 & 7 \\
\hline Tinamidae cf. Crypturellus sp. & & & 4 & 1 & \\
\hline Pelecanus sp. & pelícano & & & 83 & 5 \\
\hline Phalacrocorax sp. & cormorán & & & 2.023 & 28 \\
\hline Phalacrocorax bougainvillii & guanay & 3 & 1 & 346 & 40 \\
\hline Sula sp. & piqueros & & & 1.214 & 40 \\
\hline Phalacrocoracidae/Sulidae & cormoranes/piqueros & & & 413 & 0 \\
\hline Calidris sp. & playero enano & & & 5 & 2 \\
\hline Passeriformes & pájaros cantores, avecillas & & & 2 & 2 \\
\hline cf. Passeriformes & pájaros cantores, avecillas & 2 & 1 & & \\
\hline Passeriformes/Fringilliformes & pájaros cantores, avecillas & & & 1 & 0 \\
\hline Aves nn & & (46) & 0 & $(>14.000)$ & 0 \\
\hline Total Aves & & 51 & 2 & 4.091 & 118 \\
\hline Lacertilia & lagartos & 1 & 1 & 5 & 1 \\
\hline Serpentes & serpientes & 1 & 1 & & \\
\hline Reptilia nn (Lacertilia pequeño) & reptil indet. & 123 & 1 & 1 & 0 \\
\hline Total Reptilia & & 125 & 3 & 6 & 1 \\
\hline Tetrapoda nn (pequeño) & & 50 & 0 & 14 & 0 \\
\hline Clupeidae & arenques, sardinas & 4 & 2 & 3 & 1 \\
\hline Clupeidae/Engraulidae & arenques, sardinas/anchovetas, anchoas & 1 & 0 & 7 & 0 \\
\hline Engraulidae & anchovetas, anchoas & & & 1.507 & 31 \\
\hline Carangidae/Sciaenidae & $\begin{array}{l}\text { casabas, cocineros, jureles, fortunas/corvinatas, } \\
\text { corvinas, lornas }\end{array}$ & 1 & 0 & 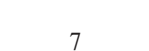 & 0 \\
\hline cf. Mugil sp. & cf. lisa & & & 2 & 1 \\
\hline cf. Sciaenidae/Carangidae & casabas, cocineros, jureles, fortunas/corvinatas, & & & & \\
\hline & corvinas, lornas & & & 1 & 0 \\
\hline $\begin{array}{l}\text { Sclaena deliclosa } \\
\text { cf. Sciaenidae }\end{array}$ & $\begin{array}{l}\text { lorna } \\
\text { cf. corvinitas, corvinas, lornas }\end{array}$ & $\begin{array}{l}4 \\
1\end{array}$ & $\begin{array}{l}3 \\
1\end{array}$ & & \\
\hline Osteichthyes uid & peces óseos & 69 & $\{3\}$ & 1.497 & $\{3\}$ \\
\hline Total Osteichthyes & & 79 & 9 & 3.018 & 34 \\
\hline Total Vertebrata & & 468 & 20 & 7.175 & 160 \\
\hline Concholepas concholepas & loco, falso abalón (tolina o chanque) & 21 & 20 & & \\
\hline Fissurella sp. & lapa & 1 & 1 & & \\
\hline Gastropoda nn & & 5 & 0 & & \\
\hline Total Gastropoda & & 27 & 21 & & \\
\hline Choromytilus chorus & choro & 21 & 4 & 4 & 1 \\
\hline Mytilidae & cholgas, choros & 1 & 0 & & \\
\hline Mulinia cf. edulis & taquillas & & & 1 & 1 \\
\hline Semele cf. corrugata & & & 1 & 1 & \\
\hline Veneridae & almeja & & & 1 & 1 \\
\hline Bivalvia nn & bivalvos & 22 & 0 & 47 & 0 \\
\hline Total Bivalvia & & 44 & 4 & 54 & 4 \\
\hline Chiton sensu latu & quiton & 4 & 2 & & \\
\hline Balanus sp. & & 17 & 0 & & \\
\hline Mollusca nn & moluscos marinos indet. & 215 & 0 & 269 & 0 \\
\hline Total Invertebrata & & 307 & 27 & 323 & 4 \\
\hline Muestra Total & & 775 & 47 & 7.498 & 164 \\
\hline
\end{tabular}



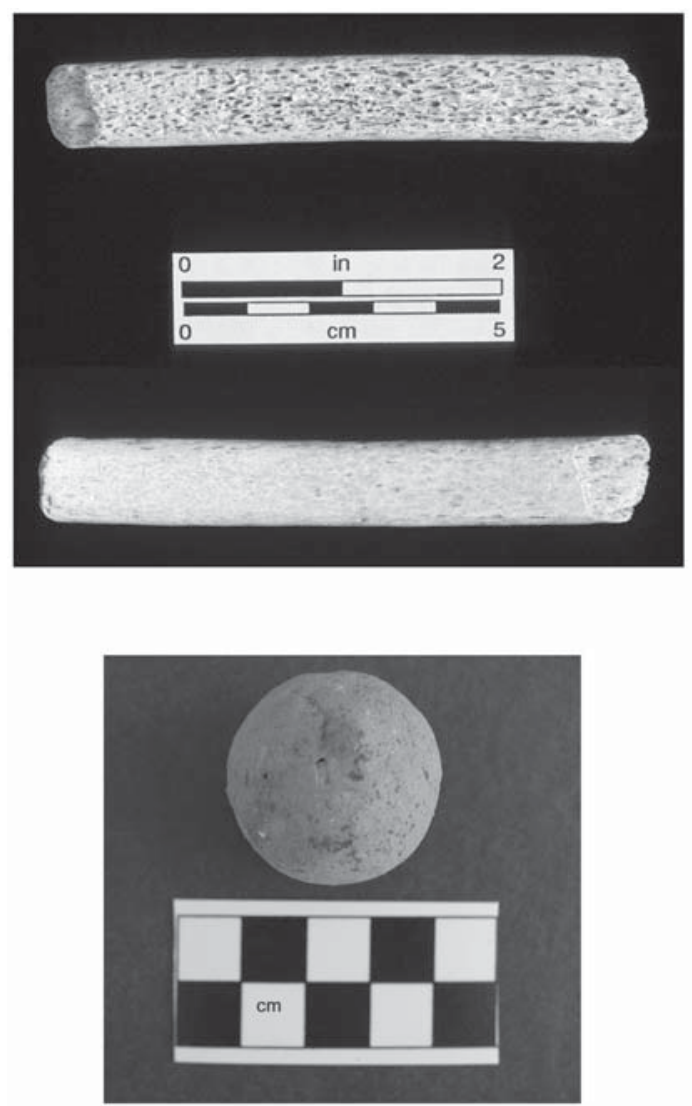

Figura 7. Artefactos no líticos. Arriba: costilla de mamífero marino trabajada, posible calibrador de red. Inferior: artefacto de arcilla de Quebrada Tacahuay.

Non-lithic artifacts. Top: worked marine mammal rib, possible net mesh gauge. Bottom: clay artifact from Quebrada Tacahuay.

consumidas durante la ocupación más temprana del sitio (e.g., tolinas, lapas y chitones). Interesantes, son los depósitos de la Unidad 5 que contienen restos de lorna (Sciaena deliciosa), la cual es también la especie más común en los depósitos de Quebrada Jaguay, un sitio marítimo temprano a unos 200 $\mathrm{km}$ al norte de Tacahuay (McIinnis 1999; Sandweiss et al. 1998). Los restos de un pequeño cánido, un probable zorro, son la única evidencia de un mamífero terrestre. A pesar que las poblaciones etnográficas en Tierra del Fuego consumieron zorros durante tiempos históricos (Stuart 1972, citado en Santoro 1993), éstos no son un recurso de subsistencia significativo en el componente del período Arcaico en esta área de la costa peruana (Rasmussen 1998; Sandweiss et al. 1998). Los especímenes de Tacahuay no contienen evidencia de descarnado, por lo que estos restos pueden o no representar evidencia de basura alimenticia.

El componente lítico del 2001 perteneciente a la ocupación más temprana contiene ocho instrumentos raspadores/cuchillos unifaciales de calcedonia (Figura 9). Estos implementos son similares a los líticos encontrados durante las temporadas de campo previas. También se encuentran cuarzo rosado en bruto $(n=6)$ y lascas de basalto $(n=4)$. Recuperamos dos núcleos de basalto y un chancador o percutor también de basalto. Los depósitos de la Unidad 8 contienen abundante desecho, principalmente pequeñas y delgadas lascas retocadas y usadas de calcedonia $(n=>900)$. Los depósitos de la Unidad 5 contienen lascas de calcedonia utilizada $(n=1)$ y no utilizada $(n=5)$, así como un pequeño número de lascas de basalto no utilizado $(\mathrm{n}=2)$. El único instrumento presente es el raspador del Rasgo 1. Desechos de calcedonia son también comunes en los depósitos de la Unidad $5(n=243)$.

El único artefacto no lítico recuperado en la temporada del 2001 es una pequeña bola de arcilla no cocida de aproximadamente $2,5 \mathrm{~cm}$ de diámetro, encontrada en el Bloque 3, Unidad 8B, entre los Rasgos 2 y 4, pero no dentro de un fogón (ver Figura 7, inferior). De forma esférica, está hecha de limo arenoso de color rojizo, probablemente el mismo material de la Unidad 8C. No presenta ranuras u otro tipo de modificación que indique su uso como boleadora; y como no está cocida, no puede haber sido un peso de red, por lo que su función es desconocida.

\section{Discusión}

La temporada de campo del 2001 consistió en la excavación de $100 \mathrm{~m}^{2}$ de depósitos del sitio y la recolección de muestras volumétricas a lo largo de un perfil previamente estudiado. Estas investigaciones amplían significativamente nuestro entendimiento del uso diacrónico del sitio y su proceso de formación. También confirman las interpretaciones previas sobre la economía del sitio y su comportamiento centrado en la adquisición de materia prima y alimentos locales. Nuestras investigaciones no han proporcionado ningún tipo de material procedente de otras regiones geográficas o elevaciones. El material para este período de tiempo (Pleistoceno tardío) se compone exclusivamente de instrumentos de piedra utilitarias con la excepción 

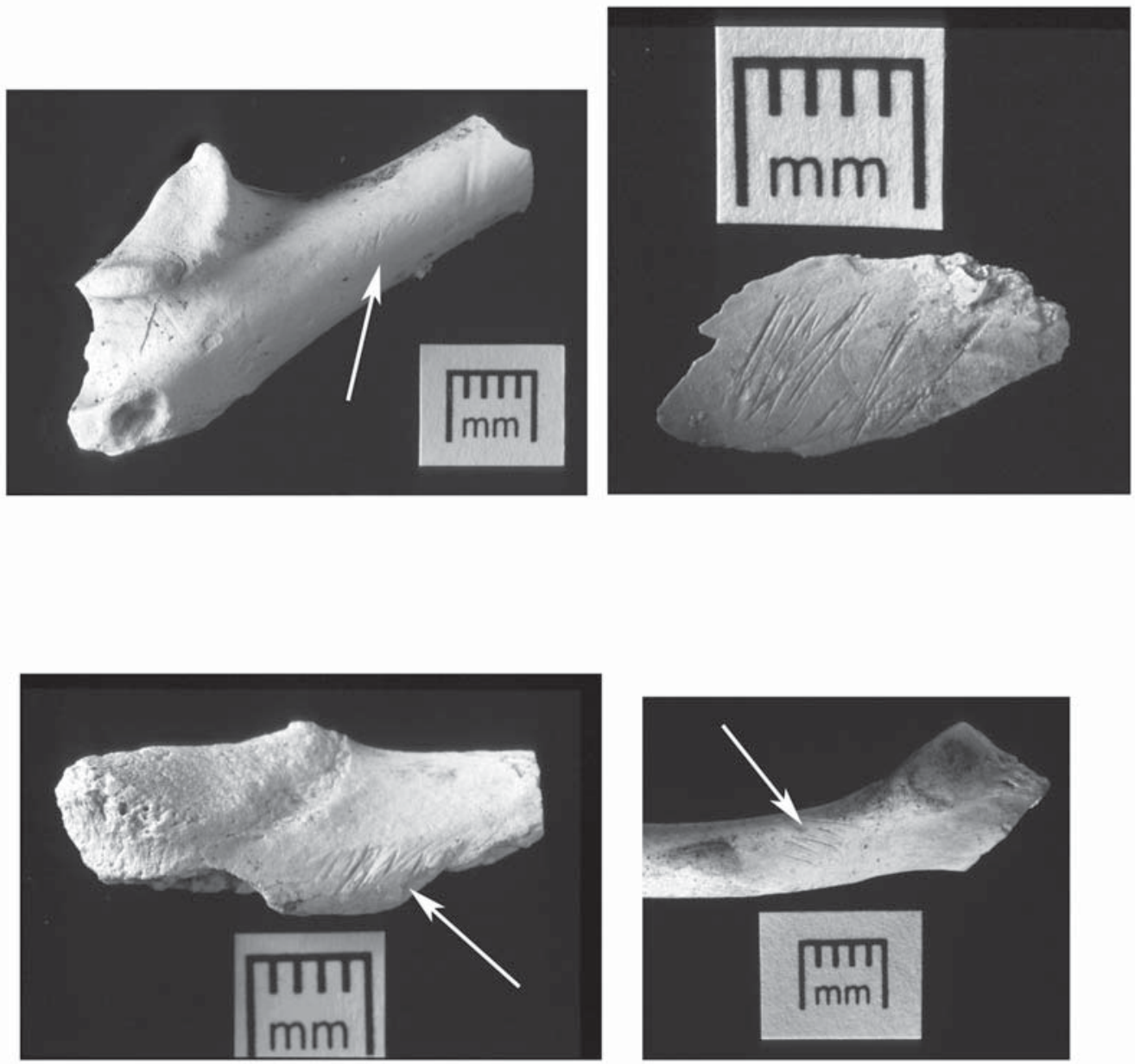

Figura 8. Ejemplos de elementos óseos marinos descarnados; todos los especímenes muestran cortes múltiples de instrumento de piedra. Arriba izquierda: coracoide de piquero; arriba derecha: hueso de ave. Abajo izquierda: coracoide de cormorán; abajo derecha: escápula de cormorán.

Examples of butchered marine skeletal elements; all specimens exhibit multiple cuts from stone tools. Top left: booby coracoid; top right: bird shaft. Bottom left: cormorant coracoid; bottom right: cormorant scapula.

de un artefacto de hueso (temporada de campo de 1998) y la inusual bola de arcilla de las investigaciones más recientes.

Mientras estos estudios han definido la economía del sitio, varios aspectos del comportamiento asociados con el uso de los recursos costeros durante finales del Pleistoceno continúan siendo desconocidos. La naturaleza de la residencia costera y movimiento poblacional para la gente relacionada con la Quebrada Tacahuay es todavía incierta. El grado de especialización costera en Tacahuay no sugiere un uso al azar u oportunístico de los hábitats de la costa (deFrance en revisión a). La especiali- zación económica y de subsistencia apoya un modelo de residencia costera; sin embargo, sin datos empíricos sobre estructuras costeras o residenciales es imposible definir los patrones territoriales de uso del espacio. No se han encontrado huellas de postes o evidencia de estructuras en la gran área expuesta durante la temporada del 2001. Dentro de la región estudiada de Tacahuay no existen materiales exóticos que puedan indicar movimientos de población hacia otras alturas o interacciones con poblaciones de otras regiones para la adquisición de materia prima. Debemos agregar que el reconocimiento de la quebrada y regiones adyacentes des- 

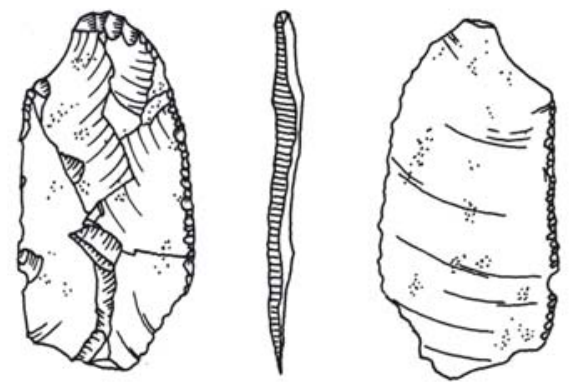

\section{Bloque 3, Rasgo 4}
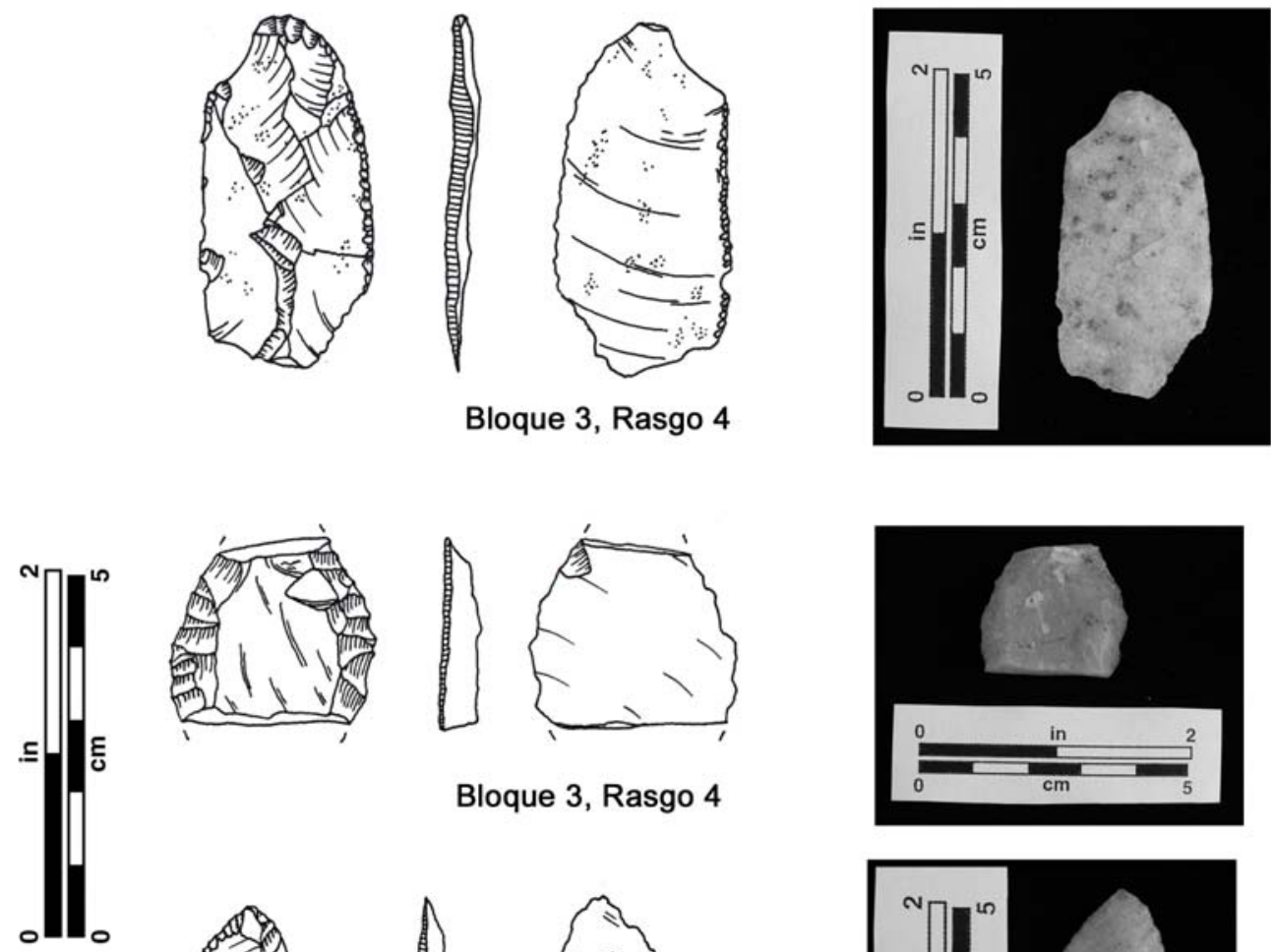

Bloque 3, Rasgo 4
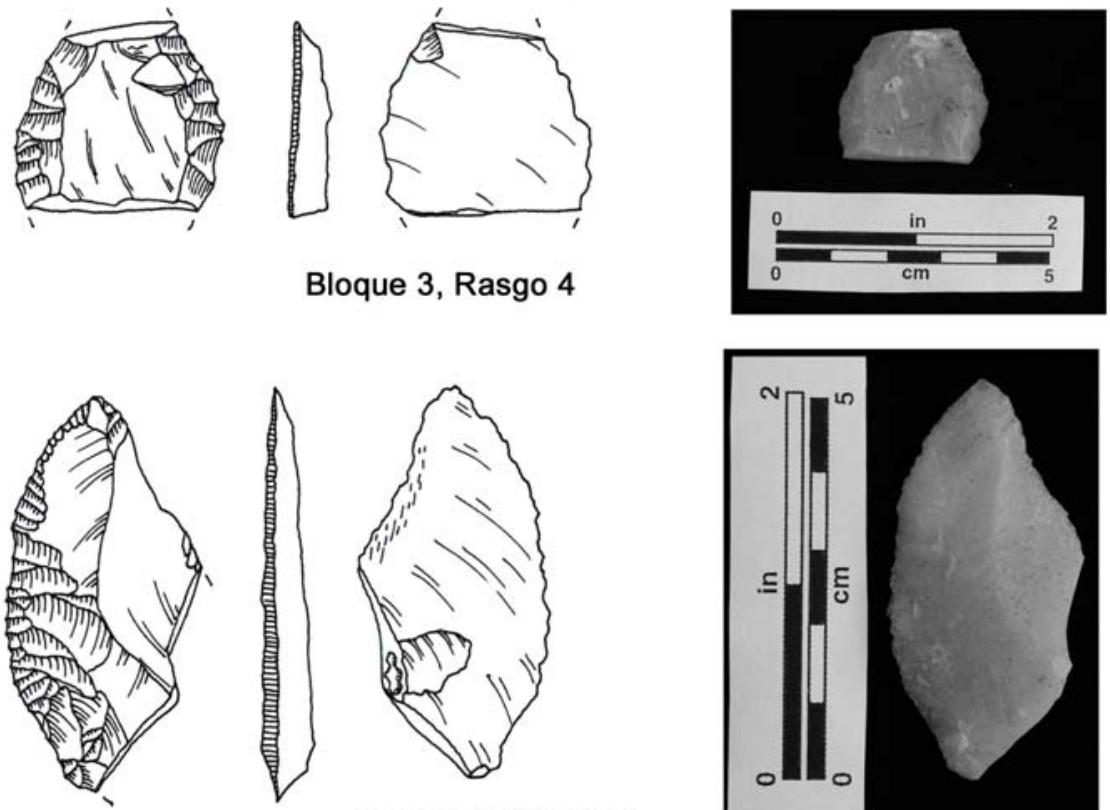

Bloque 3, Rasgo 2

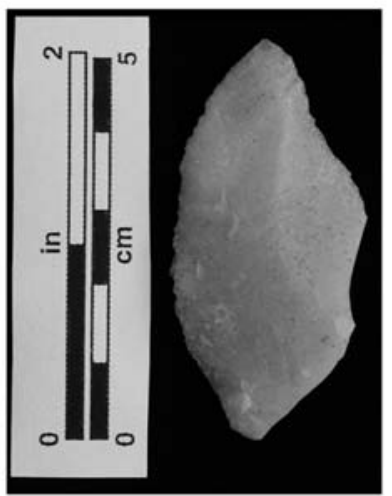

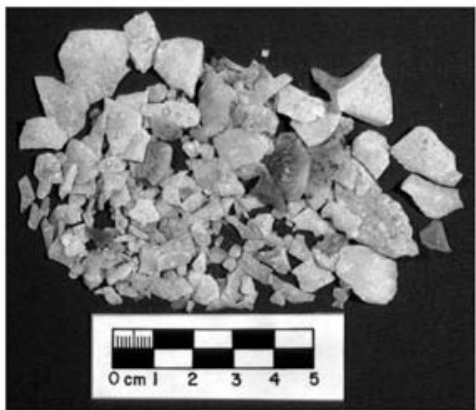

Lascas y desechos líticos

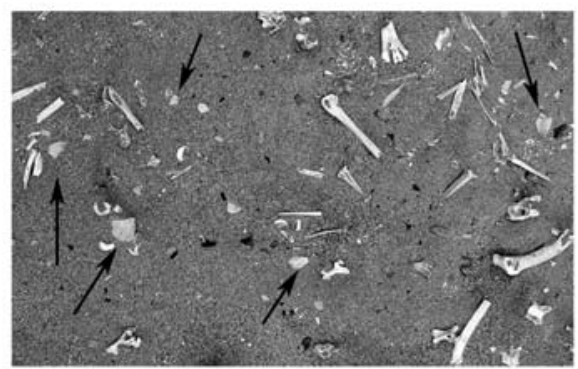

Lascas, carbón y huesos en bloque 3

Figura 9. Ejemplos de artefactos líticos de la Unidad 8. Tres ejemplos de instrumentos raspador/cuchillo descubiertos en el Bloque 3. Inferior izquierdo: desecho lítico. Inferior derecho: lascas in situ en el Bloque 3.

Examples of lithic artifacts from Unit 8. Three examples of cutting/scraping tools recovered from Block 3. Lower left: lithic debitage. Lower right: in situ flakes in Block 3. 
de la costa hasta las zonas altas de la región no ha identificado sitios contemporáneos al Pleistoceno tardío (Umire 1998).

Si no existió una población permanente en Tacahuay, es posible que una residencia más permanente pueda haberse dado en sitios a lo largo de la costa en donde existe una profunda acumulación de basura, como en el Sitio Anillo (20 km al norte de Tacahuay) o tal vez en sitios aún no identificados a lo largo de la costa (deFrance en revisión a). El Sitio Anillo es un fuerte candidato, como campamento más permanente, dado que sus depósitos datan alrededor de 10.500 años a.p. y presenta una larga secuencia de uso durante el período Arcaico (Sandweiss et al. 1989). Si se practicó un movimiento hacia el interior con fines de subsistencia, proponemos que éste podría haberse dado más allá de la cordillera de la costa, pero no en elevaciones mayores de $1.000 \mathrm{msm}$. Un patrón de migración que no necesitara de adaptaciones fisiológicas hacia los cambios de altura podría haber sido biológicamente ventajoso (Aldenderfer 1998; deFrance en revisión a; Richardson 1992).

En consecuencia, para la costa peruana de los Andes Centro-Sur, el escenario del litoral fue abundante en recursos alrededor de 10.000 años a.p. La fauna del Pleistoceno tardío explotada en Tacahuay se encuentra aún presente en la región. Los recursos costeros en los alrededores de Tacahuay no están sujetos a fluctuaciones estacionales en su disponibilidad; por lo tanto, no existió una necesidad de emigrar hacia otras áreas en busca de recursos complementarios de subsistencia. En contraste, la aparente confianza exclusiva en los alimentos costeros y recursos locales encontrados en la Quebrada Tacahuay, los contextos del Pleistoceno tardío de Quebrada Jaguay ubicada a aproximadamente a $220 \mathrm{~km}$ al norte de Tacahuay contienen evidencia para la subsistencia marítima intensiva, así como para la adquisición de materia prima de altura (obsidiana) y algunos recursos botánicos de altura (Sandweiss et al. 1998). En algunas otras áreas de los Andes Centro-Sur los investigadores han identificado patrones de migración costa-interior en asociación con ocupaciones arcaicas más recientes que incluyen asentamientos tierra dentro con basura costera así como cazadores-recolectores explotando hábitats o adquiriendo recursos en un rango de elevación desde la costa hasta las zonas altas (Llagostera 1989; Núñez 1983, 1999; Núñez et al. 1994; Santoro 1993). La explotación del hábitat de lomas (oasis dependiente de la neblina que se forma a lo largo de las laderas costeras de elevaciones bajas) está sustentado más fuertemente con el dato arqueológico. Si el agua fue un recurso limitado en el escenario costero durante el Pleistoceno tardío, los pobladores pudieron haber creado métodos de almacenamiento que no dejaran evidencias arqueológicas. Con un régimen activo del ENSO hacia el final del Pleistoceno, la flexibilidad en las estrategias de subsistencia podría haber sido beneficiosa; no obstante lo anterior, no tenemos evidencias para la cuenca de Osmore Bajo de un patrón estacional de migración de campamentos logísticos que envolvieran la explotación de recursos alimenticios de tierra adentro tales como mamíferos terrestres. La naturaleza y motivos de la interacción temprana costa-tierra adentro merece más discusión e investigación.

En relación a las condiciones medioambientales, es también evidente que las perturbaciones de El Niño causaron inundaciones durante el período de asentamiento humano inicial en la costa andina (Keefer et al. 1998; 2003). Sin embargo, se sabe poco de la reacción y adaptación humana hacia los cambios en el medio ambiente hacia el fin de la era glacial. Los objetivos de investigaciones futuras en sitios tempranos del litoral andino deberían dirigirse hacia la territorialidad, patrones de residencia y variabilidad geográfica en las adaptaciones del Pleistoceno tardío.

\section{Conclusiones}

Se condujeron tres temporadas de investigación en la Quebrada Tacahuay. Investigaciones a pequeña escala fueron completadas entre 1997 y 1998. La temporada de campo del 2001 fue más intensiva mediante la excavación de cuatro bloques de 5 x $5 \mathrm{~m}$, así como la recolección de muestras volumétricas de un perfil. Estas excavaciones de bloques dieron muy buenos resultados en la exposición de tres depósitos culturales en las Unidades 2,4 y 5 , que no fueron uniformes a través del sitio.

En uno de los cuatro bloques, el Bloque 3, los depósitos de la Unidad 5B y la Unidad 8 estaban mejor conservados. Se excavó abundante basura doméstica, instrumentos líticos y seis fogones. Dentro de los depósitos de la Unidad 8 (Pleistoceno final) la superposición estratigráfica de algunos rasgos y el enterramiento de otros por arena eólica indican que el sitio fue reusado en más de una opor- 
tunidad; los fechados radiocarbónicos y los sigmas sugieren que el sitio fue usado alrededor de varios siglos. Los restos de subsistencia y material lítico sustentan las interpretaciones previas, que la ocupación más antigua fue de carácter local extractivo donde las aves marinas y algunos otros recursos marinos fueron procesados, preparados y consumidos in situ.

Las investigaciones futuras deberán ser dirigidas a identificar la naturaleza de los asentamientos costeros, residencia y migración en el sur del Perú. También es necesario un amplio nivel de investigación del rango de la variación geográfica en las adaptaciones de subsistencia hacia el fin del Pleistoceno y durante el Holoceno temprano. Las investigaciones en la Quebrada Tacahuay demuestran que el entendimiento de la dinámica del paisaje y su papel en el enterramiento y preservación de los depósitos culturales ayuda a aclarar algunos de los fundamentos marítimos tempranos.
Agradecimientos: Esta investigación fue apoyada por FERCO, una Fundación de las Islas Canarias, creada en honor a la vida e investigación de Thor Heyerdahl, y la The National Geographic Society, Beca \# 6963-01. La temporada de campo de 1998 fue financiada por la H. John Heinz III, Fund Grant Program for Latin American Archaeology. Agradecemos a quienes nos ayudaron durante la temporada de campo del 2001: Ana Miranda, Erin Kennedy, Anna Wright y todo nuestro equipo en el campo. David Steadman identificó algunos de los elementos óseos de la avifauna. Susan Duser ayudó en la producción de la Figura 6. Mónika Barrionuevo hizo la traducción del inglés al castellano. David Keefer y Ana Miranda proporcionaron comentarios en una versión preliminar de este artículo. También agradecemos a la Universidad de Florida y al Museo Contisuyo por todo su apoyo y a los evaluadores anónimos de Chungara. Todas las omisiones y errores son nuestros.

\section{Referencias Citadas}

Aldenderfer, M. S.

1998 Montane Foragers: Asana and the South-Central Andean Archaic. Iowa University Press, Iowa.

Bard, E., B. Hamelin, M. Arnold, L. Montaggioni, G. Cabioch, G. Faure y F. Rougerie

1996 Deglacial sea-level record from Tahiti corals and the timing of global meltwater discharge. Nature 382:241.

Clement, C. O. y M. E. Moseley

1991 The spring-fed irrigation system of Carrizal, Peru: A case study of the hypothesis of agrarian collapse. Journal of Field Archaeology 18:425-444.

Cole, J.

2001 A slow dance for El Niño. Science 291:1496-1497.

Craig, A. K.

1992 Archaeological occurrences of Andean land snails. Andean Past 3:127-136.

deFrance, S. D.

En revisión a, Human use of the Andean littoral during the Late Pleistocene: implications for social and economic behavior. 2004 Chac-Mool Conference Proceedings.

En revisión b, Quebrada Tacahuay and early maritime foundations on the far southern Peruvian coast: The 2001 field season. The Foundations of Andean Civilization: Papers in Honor of Michael E. Moseley, editado por Joyce Marcus, Charles Stanish y Patrick Ryan Williams, Volume 1, Maritime Foundations: The Coastal Preceramic. Cotsen Institute of Archaeology, University of California, Los Angeles (en edición).

2002 Late paleoindian use of coastal resources at Quebrada Tacahuay: 2001 field season. Ponencia presentada en Annual Meeting of the Northeastern Conference on Andean Archaeology and Ethnohistory, Pittsburgh.
deFrance, S. D., M. E. Moseley y D. K. Keefer

1998 An early maritime adaptation on the southern coast of Peru: preliminary results from Quebrada Tacahuay. Ponencia presentada en el $63^{\text {rd }}$ Annual Meeting of the Society for American Archaeology, Seattle.

deFrance, S. D., A. Umire A, J. B. Richardson, D. K. Keefer y D. R. Satterlee

1999 Quebrada Tacahuay, an early Andean maritime occupation: results from the 1998 season. Ponencia presentada en el 64th Annual Meeting of the Society for American Archaeology, Chicago.

deFrance, S. D., D. K. Keefer, J. B. Richardson III y A. Umire A. 2001 Late Paleo-Indian coastal foragers: specialized extractive behavior at Quebrada Tacahuay, Peru. Latin American Antiquity 12:413-426.

Fontugne, M., R. Usselmann, D. Lavallée, M. Julien y C. Hatté 1999 El Niño variability in the coastal desert of southern Peru during the mid-Holocene. Quaternary Research 52:171-179.

Hughen, K. A., D. P. Schrag, S. B. Jacobsen y W. Hantoro 1999 El Niño during the last interglacial period recorded by a fossil coral from Indonesia. Geophysical Research Letters 26:3129-3132.

Keefer, D. K., S. D. deFrance, M. E. Moseley, J. B. Richardson III, D. R. Satterlee y A. Day-Lewis

1998 Early maritime economy and El Niño events at Quebrada Tacahuay. Science 281:1833-1835.

Keefer, D. K., M. E. Moseley y S. D. deFrance

2003 A 38000-year record of floods and debris flows in the Ilo region of southern Peru and its relation to El Niño events and great earthquakes. Paleogeography, Palaeoclimatology, Palaeoecology 194:41-77. 
Llagostera, A.

1989 Caza y pesca marítima. En Culturas de Chile, Prehistoria desde sus Orígenes hasta los Albores de la Conquista, editado por J. Hidalgo, V. Schiappacasse, H. Niemeyer, C. Aldunate e I. Solimano, pp. 57-79. Editorial Andrés Be1lo, Santiago.

1992 Early occupations and the emergence of fishermen on the Pacific coast of South America. Andean Past 3:87-109.

McInnis, H.E.

1999 Subsistence and Maritime Adaptations at Quebrada Jaguay, Camana, Peru: A Faunal Analysis. Tesis de Master no publicada. Institute for Quaternary Studies, University of Maine.

Núñez, L.

1983 Paleo-Indian and Archaic cultural periods in the arid and semiarid regions of northern Chile. En Advances in World Archaeology, Vol. 2, editado por F. Wendorf and A. Close, pp. 161-203. Academic Press, New York.

1999 Archaic adaptation on the South-Central Andean coast. En Pacific Latin America in Prehistory: The Evolution of Archaic and Formative Cultures, editado por M. Blake, pp. 199-212. Washington State University Press, Pullman.

Núñez, L., J. Varela, R. Casamiquela y C. Villagrán 1994 Reconstrucción multidisciplinaria de la ocupación de Quereo, centro de Chile. Latin American Antiquity 5:99118.

ONERN (Oficina Nacional de Evaluación de Recursos Naturales)

1976 Inventario, Evaluación y Uso Racional de los Recursos Naturales de la Costa: Cuencas de los Ríos MoqueguaLocumba-Sama y Caplina. Volumen I: Informe.

Rasmussen, K. A.

1998 Exploring the Origin of Coastal Sedentism in the SouthCentral Andes. Tesis Doctoral no publicada, University of California, Santa Barbara. University Microfilms, Ann Arbor.

Richardson, J. B., III

1992 Early hunters, fishers, farmers and herders: diverse economic adaptations in Peru to 4500 B.P. Revista de Arqueología Americana 6:71-90.

1998 Looking in the right places: Pre-5000 B.P. maritime adaptations in Peru and the changing environment. Revista de Arqueología Americana 15:33-56.

Riedinger, M.A., M. Steinitz-Kannan, W.M. Last y M. Brenner $2002 \mathrm{~A} \sim 6100{ }^{14} \mathrm{C}$ yr record of El Niño activity from the Galápagos Islands. Journal of Paleolimnology 27:1-7.

Rodbell, D. T., G. O. Seltzer, D. M. Anderson, M. B. Abbot, D. B. Enfield y J. H. Newman

1999 An 15,000-year record of El Niño-driven alluviation in southwestern Ecuador. Science 283:516-520.

Rollins, H.B., J.B. Richardson, III y D.H. Sandweiss 1986 The birth of El Niño: geoarchaeological evidence and implications. Geoarchaeology 1:3-15.
Sandweiss, D.H.

1986 The beach ridges at Santa, Peru: El Niño, uplift, and prehistory. Geoarchaeology 1:17-28.

2003 Terminal Pleistocene through Mid-Holocene archaeological sites as paleoclimatic archives for the Peruvian coast. Paleogeography, Palaeoclimatology, Palaeoecology 194:23-40.

Sandweiss, D.H., J.B. Richardson III, E.J. Reitz, J.T. Hsu y R.A. Feldman

1989 Ring Site. En Ecology, Settlement, and History in the Osmore Drainage, Peru, editado por D. Rice, C. Stanish, y P. R. Scarr, pp. 35-84. British Archaeological Reports International Series 545i.

Sandweiss, D.H., J.B. Richardson, III, E.J. Reitz, H.B. Rollins y K.A. Maasch

1996 Geoarchaeological evidence from Peru for a 5000 years B.P. onset of El Niño. Science 273:1531-1533.

1997 Determining the early history of El Niño-Response. Science 276:966-967.

Sandweiss, D. H., H. McInnis, R. L. Burger, A. Cano, B. Ojeda, R. Paredes, M. C. Sandweiss y M. D. Glascock

1998 Quebrada Jaguay: early South American maritime adaptations. Science 281:1830-1832.

Sandweiss, D.H., K.A. Maasch, R.L. Burger, J.B. Richardson, III, H.B. Rollins y A. Clement

2001 Variation in Holocene El Niño frequencies: climate records and cultural consequences in ancient Peru. Geology 29:603-606.

Santoro, C.

1993 Complementariedad ecológica en las sociedades arcaicas del área centro sur andina. En Acha-2 y Los Orígenes del Poblamiento Humano en Arica, editado por I. Muñoz, B. Arriaza y A. Aufderheide, pp. 133-150. Ediciones Universidad de Tarapacá, Arica.

Stuart, D. E.

1972 Band Structure and Ecological Variability: The Ona and the Yahgan of Tierra del Fuego. Tesis Doctoral no publicada, Department of Anthropology, University of New Mexico, Albuquerque.

Stuiver, M., P. J. Reimer, E. Bard, J.W. Beck, G. S. Burr, K.A.

Hughen, B. Kromer, G. McCormac, J. Van Der Plicht y M. Spurk 1998 INTCAL98 radiocarbon age calibration 24,000-0 cal BP. Radiocarbon 40:1041-1083.

Tudhope, A.W, C. P. Chilcott, M. T. McCulloch, E. R. Cook, J. Chappell, R. M. Ellam, D. W. Lea, J. M. Lough y G. Shimmield

2001 Variability in the El Niño-southern oscillation through a glacial-interglacial cycle. Science 291:1511-1517.

Umire Álvarez, A.

1998 Inventario arqueológico de la costa sur de Ilo, Proyecto Costanero III. Informe en posesión del Instituto Nacional de Cultura, Lima y el Museo Contisuyo, Moquegua, Perú. 


\section{Notas}

1 Exclusivo de las decenas de metros de estratos geológicos presentes en el canal de la quebrada principal, alrededor de $10 \mathrm{~m}$ de profundos depósitos estratificados (Unidades 122) fueron expuestos en Tacahuay en el perfil de la carretera y en el perfil del curso de agua paralelos al canal; sin embargo, sólo la Serie Superior contiene evidencia de ocupación humana (ver Keefer et al. 2003).

2 En 1997 estudiamos muestras volumétricas (0,3 a 2 litros) procedentes de áreas lineares $(0,50 \mathrm{~m}$ a $2 \mathrm{~m}$ de largo $)$ a lo largo de cuatro perfiles (Keefer et al. 1998). En 1998 se tomaron muestras volumétricas ( 0,5 a 5 litros) de 46 áreas lineares a lo largo de seis perfiles y completamos la excavación de contextos de ocho cuadrículas de 1 x $1 \mathrm{~m}$ y una de 2 x 1,5 m (deFrance et al. 2001).
3 Nosotros obtuvimos una fecha $\mathrm{C}_{14}$ anómala procedente de una raíz carbonizada presumiblemente contaminada del Bloque 1, Unidad 8C (los depósitos delgados de limo color gris rojizo que están bajo el material cultural de la Unidad 8). Siguiendo la excavación de la Unidad y la exposición del delgado lente de limo, se recuperaron algunos fragmentos pequeños de raíces carbonizadas de incrustados en el limo para fechados AMS. La muestra produjo una fecha de $3.170 \pm 40$ (años a.p.). Las raíces carbonizadas de las Unidades 2 y 3 produjeron fechas que fueron consistentes con la secuencia estratigráfica (Keefer et al. 1998), por lo que se cree que esta muestra anómala estaba probablemente contaminada. 